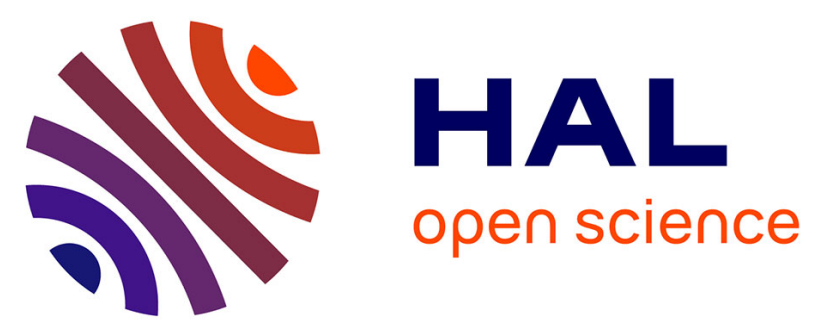

\title{
Influence of Lateral Heterogeneities on Strong Motion Shear Strains: Simulations in the Historical Center of Rome (Italy)
}

S Martino, L Lenti, C Gélis, Anna Chiara Giacomi, Maria Paola Santisi d'Avila, Luis Fabian Bonilla, F Bozzano, J.-F. Semblat

\section{To cite this version:}

S Martino, L Lenti, C Gélis, Anna Chiara Giacomi, Maria Paola Santisi d'Avila, et al.. Influence of Lateral Heterogeneities on Strong Motion Shear Strains: Simulations in the Historical Center of Rome (Italy). Bulletin of the Seismological Society of America, 2015, 105 (5), 21p. 10.1785/0120140180 . hal-01283575

\section{HAL Id: hal-01283575 \\ https://hal.science/hal-01283575}

Submitted on 7 Mar 2016

HAL is a multi-disciplinary open access archive for the deposit and dissemination of scientific research documents, whether they are published or not. The documents may come from teaching and research institutions in France or abroad, or from public or private research centers.
L'archive ouverte pluridisciplinaire HAL, est destinée au dépôt et à la diffusion de documents scientifiques de niveau recherche, publiés ou non, émanant des établissements d'enseignement et de recherche français ou étrangers, des laboratoires publics ou privés. 
Influence of lateral heterogeneities on strong motion shear strains: simulations in the historical center of Rome (Italy)

\author{
F. Bozzano ${ }^{1}$, J.F. Semblat ${ }^{2}$
}

\footnotetext{
${ }^{1}$ University of Rome "Sapienza”, Dipartimento di Scienze della Terra and Centro di Ricerca Previsione, Prevenzione e Controllo dei Rischi Geologici (CERI) - P.le A. Moro 5, 00185 , Roma.

${ }^{2}$ Université Paris-Est, Institute of Science and Technology for Transport, Development and Networks (IFSTTAR), 14-20 Boulevard Newton Cité Descartes, Champs sur Marne F- 77447 Marne la Vallée, France

${ }^{3}$ Institute for Radiological protection and Nuclear Safety (IRSN),_PRP-DGE/SCAN department, B.P.17,92262 Fontenay-aux-Roses Cedex, France

${ }^{4}$ University of Nice-Sophia Antipolis, Laboratoire Jean Alexandre Dieudonné, 28, Avenue Valrose, 06108 Nice, France

*corresponding Author: salvatore.martino@uniroma1.it
}

(15)

\title{
Abstract
}

The influence of lateral heterogeneities in alluvial deposits represents a topic of particular interest in the field of urban planning and engineering design of structure and infrastructures. This work is focused on the effects of such heterogeneities on the shear strains produced within the recent alluvial deposits of the Tiber River in Rome historical center in case of the worst expected earthquake scenario. At this aim, a 3D engineering-geology model of the subsoil is used to derive 4 geological sections across the Tiber River valley as well as 48 soil columns in order to perform numerical simulations. Various models are considered: a viscoelastic equivalent linear rheology in a 1D finite difference model for one motion component (EERA code), a nonlinear elasto-plastic model in a 1D finite element scheme for three motion components and a nonlinear visco-elasto- 
plastic rheology in a 2D finite difference model under one-component horizontal input. As it results from comparing these different simulations, the lateral heterogeneities play a key role with respect to the expected shear strains within multilayered soils. At this aim some specific indexes are introduced to estimate the maximum shear strain concentration index within the soil layers as well as to highlight their effect due to the stratigraphic position of the layers, within the soil column, independently from its depth. A final differential index leads to the evaluation of the lateral heterogeneity effect on the estimated maximum shear strain, demonstrating their prevalent role with respect to the bedrock shape (i.e. the angle of inclination of the buried valley slopes). From these results, a maximum shear strain zoning map is obtained for the historical center of Rome, showing that the local seismic response should be modeled by assuming 1D or 2D conditions depending on the location considered.

\section{Keywords}

Lateral heterogeneities, strong motion, site effects, earthquake-induced strains, numerical modeling, Rome

\section{Introduction}

Local seismic response in large urban areas is often estimated through one-dimensional (1D) and two-dimensional (2D) numerical simulations (Rovelli et al., 1994, 1995; Panza et al., 2004; Bozzano et al., 2008; Bonilla et al., 2010; Bonilla et al., 2006; Bouden-Romdhane et al., 2003; Semblat and Pecker, 2009). During the last decades multi-dimensional seismic wave amplification have been pointed out in different basins from noise and weak-motion records. This topic is particularly important in urban areas where the original morphology of the natural valley can be hidden also by the presence of human structures and infrastructures (Rassem et al., 1997; Semblat et al., 2000, 2002; Bouden-Romdhane et al., 2003; Kham et al., 2006; Sørensen et al., 2006; Semblat 
et al., 2008). 2D amplification effects can be detected by seismometric measurements but a significant effort needs to be done to relate them to geological constraints (Di Giulio et al., 2008; Lenti et al., 2009), especially in the case of heterogeneous valley fills or of irregular bedrock geometries. In this regard, previous studies were mostly focused on the effects related to the impedance contrast among horizontal layers, i.e. few researches were devoted so far on the contrasts due to the existence of lateral contacts among different lithologies (Semblat et al., 2005; Peyrusse et al., 2014). In cases where superficial seismic measurements are not suitable since they are not representative for free-field condition as a consequence of site-city interaction effects (Kham et al., 2006; Semblat et al., 2008) and records from vertical seismic arrays are not available, an important role can be played by numerical models able to account for basin effects, i.e. multidimensional geometries and lateral soil heterogeneities.

The use of numerical methods is widespread; some experiments have demonstrated the reliability of these numerical approaches in reproducing observed local seismic effects also for irregular geometries of the fill deposits and the bedrock (Semblat et al., 2002a,b). Moreover, numerical modeling makes it possible to obtain transfer functions resulting from bedrock/outcrop ratios in both linear and nonlinear conditions (Lanzo and Silvestri, 1999) or amplification functions resulting from outcropping-fill/outcropping-bedrock ratios (Borcherdt, 1994). More recently, the percentage of non-linearity (PNL) and the associated shift frequency (Sh) parameters were introduced by Regnier et al. (2013) to describe and estimate the effects of soil nonlinear behaviour on site response.

The numerical methods were mainly devoted to analyse possible local effects due to the modification of the input seismic wavefield in the superficial layers, both in linear and non-linear conditions. The numerical models (Bard, 1983; Bard and Bouchon, 1980a, b, 1985; Mozco and Bard, 1993; Pergalani et al., 1999; Makra et al., 2005; Semblat et al., 2005; Pergalani et al., 2008; Lenti et al., 2009; Gélis and Bonilla, 2012; 2014) demonstrate that in case of basins-like systems filled by homogeneous and heterogeneous deposits, local seismic response depends on many 
features such as soil geometry, impedance contrast, dynamic properties, as well as on the stress field variations induced by the seismic motion that may lead to relevant nonlinear effects.

Among the effects related to the local seismic response, the study presented herein focuses on the analysis of earthquake-induced strains, within soil deposits that fill a basin-like system, by taking into account the heterogeneities due to both lateral and vertical contacts. In this regard, a nonlinear soil behaviour should be considered where the most severe expected earthquake scenario. At this aim, we propose an approach based on the comparison among different numerical modeling solutions to elicit the contributions due to $1 \mathrm{D}$ vs. $2 \mathrm{D}$ effects, linear vs. nonlinear soil behaviour. The effects of a multiaxial stress state in the soil, modeled by a 3D-rheology, are also investigated since they can play a significant role on the resulting nonlinear strains (Santisi d'Avila et al., 2012, 2013). Moreover, this study is particularly focused on the maximum shear strain distribution in the Rome historical centre, to get an insight for possible interaction with structure (i.e. foundations or infrastructures) by mapping where 1D approximation is sufficient to assess maximum shear strain and where prevalent $2 \mathrm{D}$ effects control.

The recent alluvial plain of the Tiber River in the historical center of Rome (Italy) was selected as study area (Fig.1) for this research because of the relevance of the historical heritage, the documented historical damages on both monuments and buildings related to the historical strong earthquakes (Ambrosini et al., 1986; Molin and Guidonboni, 1989; Donati et al., 1999; Donati et al., 2008; Bozzano et al., 2011) as well as for the geological and geotechnical data availability from previous studies (Bozzano et al., 2000; Bozzano et al., 2008; Raspa et al., 2008) (Fig. 1).

Rome is located at a distance of some tens of kilometers from the central Apennines seismogenic zone, where earthquakes of tectonic origin and of a magnitude up to 7.0 can be expected (Fig.1). The most recent major earthquake occurred on April 6 ${ }^{\text {th }}, 2009$ (Mw 6.3) close to L'Aquila city, about $100 \mathrm{~km}$ northeast (NE) from Rome (Blumetti et al., 2009) and was felt in Rome up to V MCS intensity. Smaller earthquakes, with a focal depth less than $6 \mathrm{~km}$ and maximum magnitude of 5, 
originate at the Colli Albani hills volcanic source (Amato et al., 1994). Moreover, a local seismicity in the urban area can produce earthquakes with a magnitude below 4 (Tertulliani et al., 1996); these smaller events are expected to produce a maximum intensity of VI to VII in Rome.

Several studies on the local seismic response in Rome are already available in the literature. Rovelli et al. $(1994 ; 1995)$ performed 2D finite difference simulations and a hybrid technique based on summation and finite differences was proposed by Fäh at al. (1993). This model was designed assuming a homogeneous fill of the Tiber River valley, except for a basal layer of gravels on the local seismic bedrock, and a viscoelastic rheology attributed to the alluvial soils. Olsen et al. (2006) generated a 3D velocity model for Rome embedded in a 1D regional model, considering a homogeneous fill of the Tiber River valley, and estimated long-period ( $>1 \mathrm{~s})$ ground motions for such scenarios from finite difference simulations of viscoelastic wave propagation. This model confirmed a $1 \mathrm{~Hz}$ resonance frequency for the alluvial deposits while pointed out durations much longer than those from previous studies that omitted important wave-guide effects between the source and the city. Bozzano et al. $(2000 ; 2008)$ analyzed static and dynamic geomechanical properties of the Holocene alluvial fill within the Tiber River valley and demonstrated that the siltyclay deposits, representing the most part of the Tiber alluvial body, play a key role in assessing the soil column deformation profile since it can be affected by nonlinear effects induced by the maximum expected earthquake. The first seismic ground-motion recorded in the urban area of Rome (at the Vasca Navale array) corresponds to the April 2009 L'Aquila seismic sequence (Caserta et al., 2013); the empirical soil transfer function shows a significant amplification at almost $1 \mathrm{~Hz}$ according to the 1D simulations already obtained for the same site (Bozzano et al., 2008).

Rome historical centre is a good case study to assess the role of $1 \mathrm{D}$ vs $2 \mathrm{D}$ effects as it regards the shape ratio of the bedrock in the Tiber River valley. According to Bard and Bouchon (1985), the computed values are always lower than 0.3 and therefore suitable for a 1D resonance combined to lateral wave effect. Moreover, according to Semblat et al. (2010) amplification lower than 20 
should be expected in the Tiber river valley at the fundamental frequency of about $1 \mathrm{~Hz}$ under perfectly elastic conditions. This results by considering a $\kappa_{\mathrm{h}}$ ratio $(=\mathrm{L} / \mathrm{H}$ where $\mathrm{L}=$ half length of the valley and $\mathrm{H}$ is the maximum depth) much more higher than 6 and impedance ratio $\chi$ parameter $\left(=\mathrm{Vs}_{\text {_bedrock }} / \mathrm{Vs}_{\text {_soft soil }}\right)$ ranging from 1 to 2.

\section{The Rome historical center case study}

Rome is one of the main historical cities of Italy and its political center. The millenary history of the city, its extraordinary historical heritage and the actual population of about 4 millions inhabitants entails a high vulnerability and exposure to natural risks. The actual geological setting of Rome urban area results from a recent evolution of the Tiber River alluvial valley connected to the adjacent coastal plain. Nonetheless, this evolution represents the final stage of the geodynamic processes responsible for the genesis of the Central Apennines chain (Fig. 1). Several studies contributed so far to the reconstruction of the geological setting of Rome subsoil (Corazza et al., 1999; Bozzano et al., 2000; Campolunghi et al., 2007; Bozzano et al., 2008; Raspa et al., 2008; Milli et al., 2013, Mancini et al., 2013).

The area of Rome historical center is characterised by marine sedimentary conditions from Pliocene through early Pleistocene times (4.5-1.0 myr). This Plio-Pleistocene succession consists of alternating, decimetre-thick layers of clay and sand, with an overconsolidation ratio (OCR) greater than 5 and low compressibility (Bozzano et al., 1997). Given its lithological features, the Monte Vaticano Unit (UMV) is considered to be the geological bedrock of the area of Rome. During middle-late Pleistocene and Holocene, the sedimentary processes were confined to fluvial channels and coastal plains and strongly controlled by glacio-eustatic sea-level changes (Karner and Renne, 1998; Karner and Marra, 1998, Marra et al., 1998). At the same time, this area also experienced strong volcanic activity, which caused the emplacement of a thick pyroclastic cover that became intercalated into the continental sedimentary deposits.

The current hydrographic network of the Tiber valley and its tributaries, were originated from the 
Würm glacial period (18 kyr) and it results from re-incision and deepening of valleys heredited from the previous glacial-interglacial phases.

The sediments partially filling the Holocene valleys (Bozzano et al., 2000) are generally characterised by a fining-upward succession, with a few meters thick basal layer of gravels grading into a thick pack of sands and clays (Fig. 2). This fine-grained portion of the deposit is represented by normally to weakly overconsolidated clayey and sandy silts, saturated in water, with low stiffness. According to Bozzano et al., (2000), the alluvial deposits were distinguished in 7 lithotechnical units, in the following named "layers" for simplicity. Figure 2 shows a basal G layer is constituted of coarse grained deposits, up to $10 \mathrm{~m}$ thick, covering the UMV and composed of limestone gravel in a grey sandy-silty matrix. The D layer is composed by grey coloured silty-sands passing to clayey-silts. These layers were recently distinguished in two sub-layers (Bozzano et al., 2012): the D1 sub-layer characterised by a prevalent sandy grain size; the D2 sub-layer characterized by a prevalent silty-clay grain size. The $\mathrm{C}$ layer is composed by grey clays passing to silty-clays with a variable organic content which is responsible for local dark colour; this layer is mainly located close to the boundary of the valley and, in particular, on its right side, where it reaches a maximum thickness of about $50 \mathrm{~m}$.

The clayey C layer is locally carved by some furrows filled by the B layer, which is generally composed by brown to yellow coloured sands (B1) and locally passes to silty-sands and clays (B2). The recent alluvia of the Tiber (A level) complete the sedimentary succession; these alluvia are mainly composed of silty-sands locally passing to clayey-silts, up to $15 \mathrm{~m}$ thick, in correspondence to the left side of the valley.

Finally, the $\mathrm{R}$ layer, up to $8 \mathrm{~m}$ thick, represents man-made fills, i.e. the most recent deposits which overly the Tiber alluvia and they are characterised by abundant, variously sized brick fragments and blocks of tuff embedded in a brown-green silty-sandy matrix, also including ceramic and mortar fragments. 
Based on the geomechanical characterisation by Bozzano et al. (2000; 2008), the C layer is classified as inorganic silty-clay of average-high compressibility with a very low OCR of about 1.2, whereas the UMV are defined as stiff silty-clays (OCR $\cong 6)$. Lithotypes A and D2 are defined as silty-clays with middle-low compressibility. Based on oedometer tests, the A layer clayey silts are highly overconsolidated (OCR $\approx 10)$, probably due to changes in the water table position.

The B1 layers is characterised by sand, sandy loam and sandy-clayey loam while the B2 layer is predominantly characterised by sandy loam, sandy-clayey loam with subordinate silty clay and clay of low to medium plasticity. The D1 sub-layer includes deposits with a sandy-silty grain size which were differentiated with respect to the silty-clayey D2 sub-layer on the basis of borehole logstratigraphies as well as of available grain size distributions (Bozzano et al., 2012).

Site and laboratory testing of the Tiber alluvial deposits (Bozzano et al., 2008), demonstrated that a significant difference exists between sandy or silty-clayey deposits (A, B, C, D layers) and the basal sandy gravels (G layer). In terms of shear wave (S-wave) velocity (Vs) the above mentioned difference corresponds to a $\Delta \mathrm{Vs}$ of about $300 \mathrm{~m} / \mathrm{s}$ (Fig.3a). In this regard, the $\mathrm{G}$ layer can be considered as the local seismic bedrock, since it has a Vs > $700 \mathrm{~m} / \mathrm{s}$ (Bozzano et al., 2008). Relatively low Vs values $(<600 \mathrm{~m} / \mathrm{s})$ were measured within the first $10 \mathrm{~m}$ of UMV; this finding is consistent with a softening effect related to the stress release caused by the late Pleistocene fluvial erosion (Bozzano et al., 2006). As a consequence, linearly increasing Vs values (e.g., from 540 up to $1000 \mathrm{~m} / \mathrm{s}$ ) have been assumed in the numerical models in the first 20 meters within the UMV.

The dynamic properties of the Tiber alluvial deposits were derived by resonant column and cyclic torsional shear tests assuming confining pressure in the range 200-300kPa (Bozzano et al., 2008). At low strain levels (i.e., for strain levels where no significant reduction of shear moduli are observed, strain level $<10^{-6}$ ) these tests lead to a difference between the stiffness related to the Tiber alluvia and the high consistency UMV clays of the bedrock equal to about $100 \mathrm{MPa}$. Conversely, the differences measured inside the alluvia (i.e. between $\mathrm{C}$ and A layers) are less significant and anyway in the 50-100 MPa range. The decay curves deduced from the same tests 
(Fig.3b) put in evidence that the linearity threshold $\left(\gamma_{1}\right)$ for the shear strains is of about $0.005 \%$ for the UMV and in the range $0.01 \%-0.02 \%$ for the A and C layers of the alluvial deposits, while the volume shear deformation threshold $\left(\gamma_{\mathrm{v}}\right)$ for the $\mathrm{A}$ and $\mathrm{C}$ layers ranges from $0.02 \%$ to $0.05 \%$. The D1 layer was characterised by resonant column tests on reconstituted samples (Bozzano et al., 2012). At this aim, the Proctor optimum of the granular mix was reached at a saturation of $90 \%$, with a water content $(\mathrm{w})$ of $17.6 \%$, corresponding to a density $\left(\gamma_{d}\right)$ of $16.70 \mathrm{kN} / \mathrm{m}^{3}$. Resonantcolumn tests yielded a $\gamma_{1}$ of $0.005 \%$ and a $\gamma_{\mathrm{v}}$ of $0.03 \%$. As it resulted from the laboratory tests, seven $G / G_{0}$ and $D$ vs. shear strain curves were associated to the lithotechnical units as reported in Fig.3b.

According to the resonant column tests, a hysteretic constitutive law was attributed to layers with Vs $<800 \mathrm{~m} / \mathrm{s}$; whereas a viscoelastic constitutive law was attributed to the other UMV layers (Fig.3).

\section{Numerical models}

\section{D engineering-geology model of the subsoil}

A 3D engineering-geological model of the alluvial fill in Rome historical center was reconstructed based on log-stratigraphies from 78 boreholes collected so far from literature studies and technical reports (Fig.4). The depths reached by these boreholes range from 30 up to $67 \mathrm{~m}$ b.g.l. and 28 reach the high-consistency clays of the UMV geological substratum. The 3D model reconstruction was performed by co-relating and interpolating the borehole stratigraphies on different planes with a depth interval of $5 \mathrm{~m}$ and by obtaining a vertical correlation among them (Fig.4a). The engineering-geology model was obtained by differentiating the lithotechnical units (cfr. § 2.2) and by deriving their geometries within the alluvial fill, i.e. by describing the vertical and horizontal contacts existing among them. Based on the $3 \mathrm{D}$ geological model, 12 cross sections were derived all along the Tiber River valley (displayed in Fig.1) and 48 soil 
columns were extracted along these sections. To identify the 48 columns selected along the sections a binomial label was attributed that reports the Arabic number of the section and a capital letter indicating the position of the column along the section as reported in Fig.1 (for example the $1 \mathrm{~A}$ soil column is located along section 1 at position A). As displayed in Figs.4b and $4 \mathrm{c}$, the 12 sections extracted from the 3D engineering-geological model were smoothed in order to be used for the related numerical models.

Both geological cross sections and soil columns show the high heterogeneity of alluvial deposits that fill the Tiber River valley in Rome historical center. In particular, the 3D engineeringgeological model points out that (Figure 4): the G layer is always present at the basis of the deposits, the D1 layer is generally centered with respect to the valley; the C layer fills the most part of the valley and it is inter-layered with D2 layer; the B1, B2 and A layers are distributed within the first $25 \mathrm{~m}$ b.g.l.. From the considered soil columns it is obvious that the most part of the fill is constituted by the inorganic clays ascribable to the $\mathrm{C}$ layer (i.e. almost $33 \%$ of the cumulative thickness of the alluvial deposits along the considered columns that is of about $3 \mathrm{~km}$ as shown in Fig.5a) whose thickness varies up to $50 \mathrm{~m}$ (see thickness distribution in Fig. 5b).

\section{Reference input motion}

For this study a unique three component time history representative for the maximum ground motion expected in the historical center of Rome at 475 years was considered. The reason of such a choice is that a deterministic approach for the earthquake-induced strain effects was adoptedfollowing previous studies on the seismic response in the Rome historical center (Rovelli et al., 1994; 1995; Olsen et al., 2006). In addition, a previous study by Bozzano et al. (2008) shows that inputs representative for other seismogenetic sources (such as the Colli Albani one) are not suitable for producing non linear effects within the alluvial soils of the Tiber river in the Rome urban area. No synthetic inputs were used, in agreement with the present Italian technical rule for geotechnical constructions, but time history selected among several 
natural accelerometric records collected in the European Strong-motion Database (ESD). Moreover, to avoid that specific features of the seismic input could influence the modelled seismic response, the spectral content of the selected time history was checked to have a regular distribution in a wide frequency range $(0.1-10 \mathrm{~Hz})$.

It was not possible to consider the acceleration time history of the 2009 L'Aquila mainshock recorded by the vertical array of Valco S. Paolo station in Rome (Caserta et al., 2013) since the measured peak of ground acceleration (PGA) was around $10^{-3} \mathrm{~g}$ that is two orders of magnitude (Fig. 6). lower than the current study. As a consequence, a three-component time history has been produced (Bozzano et al., 2012), taking into account the maximum PGA expected in the historical center of Rome (i.e. $0.1258 \mathrm{~g}$ at 475 years according to the project INGV-DPC 20042006). As a first step, a historical analysis of the felt seismicity was performed by considering the last 2000 years, obtaining a couple of (magnitude-distance) values representative for the maximum seismic scenario expected in Rome. These parameters allowed to select from the European Strong-motion Database (ESD) a first set of three-component time histories, representative of the maximum expected ground motion. As a second step, the response spectra (5\% inelastic damping) related to these time histories were calculated and compared to the reference response spectrum expected for Rome. The latter is already available and defined in the framework of the national project UHS INGV, Cluster 6, Central Italy. The best fit allowed selecting only one three-components time history among the whole set of data selected starting from the ESD. The horizontal component with the maximum ground acceleration value was scaled to the characteristic PGA value for the historical center of Rome. The other components were then scaled taking into account the ratios between the PGA of the three original time histories. This procedure allowed obtaining three acceleration time histories representative for the maximum ground motion expected in Rome and which were used in the numerical modeling 


\section{D numerical models}

The relevance of 1D modelling consist in providing transfer functions as well as the maximum shear strain (MSS) distribution with depth that can reveal the role of the vertical heterogeneities (i.e. layering) of the subsoil also depending on the non linear effects in case of strong motion (Bonilla et al., 2011; Regnier et al., 2013). In this study the 1D modeling was performed for the 48 selected soil columns (Table 1), using two 1D numerical wave propagation models, an equivalent linear model (EERA code by Bardet et al., 2000) and a truly nonlinear approach (SWAP_3C code by Santisi d'Avila et al., 2012), and the time histories obtained by the previous procedure. In particular, EERA allows evaluating the local seismic response of horizontally stratified soil to the one-directional wave propagation of one-component vertically incident waves, considering the equivalent linear approach in the frequency domain. Conversely, SWAP_3C can model the one-directional propagation of a three-component ground motion in a soil profile. In the SWAP_3C code, the three-dimensional nonlinear cyclic elastoplastic constitutive model, originally proposed by Iwan (Iwan, 1967; Joyner, 1975; Joyner and Chen, 1975) for dry soils, is implemented in a finite element scheme. Iwan's constitutive relationship, defined as a Masing-Prandtl-Ishlinskii-Iwan (MPII) type model by Segalman and Starr (2008), has been selected because few parameters commonly available (density and shear modulus decay curve) are necessary to characterize the soil hysteretic behaviour (Santisi d'Avila et al., 2012). The MPII model is nonlinear in loading and unloading. Shear and pressure seismic waves are simultaneously propagated along the vertical $z$-direction in a nonlinear soil profile, from the top of an underlying semi-infinite elastic seismic bedrock to the free surface. The stresses normal to the free surface are assumed null and an elastic boundary condition is imposed at the soil-bedrock interface (Joyner and Chen, 1975; Bardet and Tobita, 2001), in terms of stresses normal to the soil column base, allowing energy to be radiated back into the underlying medium, to take into account the finite rigidity of the bedrock. The multilayered soil 
is assumed of horizontal infinite extent, with consequent no strain variation in horizontal directions $x$ and $y$. At a given depth, soil is assumed to be a continuous and homogeneous medium.

This procedure can be used to evaluate the role of geotechnical and ground motion parameters affecting the soil response.

\section{D numerical models}

2D models are relevant since they point out amplification effects due to horizontal amplification functions $(\mathrm{A}(\mathrm{f}))$ as well as of MSS distribution within the alluvial body. In this regard both the $\mathrm{A}(\mathrm{f})$ and the MSS distribution can be influenced by the basin shape, the impedance contrast between soft soil and bedrock (Bard and Bouchon, 1985; Lenti et al., 2009; Semblat et al., 2010) and the non linearity effects in case of strong motion (Bonilla et al., 2005; Assimaki and Li, 2012; Gélis and Bonilla, 2012; 2014). In this study, the 2D numerical modeling was carried out on 4 among the 12 available cross sections realised across the Tiber River valley in Rome historical center (Fig.7). These selected cross sections (1, 6, 7 and 11) are representative of the alluvial fill deposit main features: i) a variable position of the D1 layer with respect to the middle portion of the valley, ii) a thickness of the upper alluvial deposit that includes layers R, A and B varying in the range $10-30 \mathrm{~m}$, iii) different lateral contacts between layer D1, D2 and C; iv) the angles of the buried valley slopes measured from the ground level to the top of the gravel varying up to $30^{\circ}$.

Finite difference (FD) stencil proposed by Saenger et al. (2000) is considered to model the 2D propagation of $\mathrm{P}$ and Vertical Shear waves (P-SV). This stencil allows computing all components of the stress-strain tensor in one point of the numerical mesh, which simplifies the implementation of the computation of nonlinear soil rheologies. Consequently wave 
propagation in heterogeneous linear and nonlinear media is efficiently modelled. Furthermore, the free surface is easily introduced by zeroing Lamé parameters above the free surface and surface waves can be modeled more accurately (Gélis et al., 2005) than with traditional staggered-grid methods (Virieux, 1986).

The models are $90 \mathrm{~m}$ deep and almost $4 \mathrm{~km}$ wide; nevertheless, the domain corresponding to the basin of each section profile was laterally extended in order to have a numerical reference in the model so that rock outcropping motions can be obtained. Furthermore, absorbing boundary conditions are guaranteed at the bottom and the sides of the model. by Day and Bradley (2001). The minimum values of the quality factor for S-waves $\left(\mathrm{Q}_{\mathrm{S}}\right)$ was directly derived from the Vs values if not directly inferred them from the Resonant Column laboratory tests. The values of the quality factor for pressure waves (P-waves) $\left(\mathrm{Q}_{\mathrm{P}}\right)$ were assumed equal to $2 \mathrm{Q}_{\mathrm{s}}$. The spatial and time discretizations were $\mathrm{dx}=0.5 \mathrm{~m}$ and $\mathrm{dt}=5 \mathrm{e}-5 \mathrm{~s}$ which permit to have reliable results in linear and nonlinear simulations up to $10 \mathrm{~Hz}$.

The strain-stress relation, governing the non linear behaviour modeling and used at each time step, is based on the multishear mechanism model proposed by Towhata and Ishihara (1985). The multishear mechanism model is a plane strain formulation to simulate pore pressure generation in sands under cyclic loading and undrained conditions. After the work by Iai et al. (1990ab), the model was modified to account for the cyclic mobility and dilatancy of sands. However, in its basic form, this formulation models the soil nonlinearity without accounting for co-seismic water pore pressures. Bonilla (2000) added the damping control to the soil constitutive model.

The multiple mechanism model relates the effective stresses $\left(\sigma^{\prime}\right)$ to the strain $(\varepsilon)$ through the following incremental equation,

$$
\left\{d \sigma^{\prime}\right\}=[G]\left(\{d \varepsilon\}-\left\{d \varepsilon_{p}\right\}\right)
$$

where the curly brackets represent the vector notation; $\left\{\varepsilon_{\mathrm{p}}\right\}$ is the volumetric strain produced by 
the pore pressure, and [G] is the tangent stiffness matrix. This matrix takes into account the volumetric and shear mechanisms, which are represented by the bulk and tangent shear moduli, respectively. The latter is idealized as a collection of I springs separated by $\Delta \theta=\pi / \mathrm{I}$. Each spring follows the hyperbolic stress-strain model (Konder and Zelasko, 1963) and the generalized Masing rules for the hysteresis process. For more details on the nonlinear stressstrain rheology, the reader may see the papers by Iai et al. (1990ab) and Bonilla (2000).

\section{Results from the models}

The numerical results are analysed in terms of amplification functions $A(f)$, expressed by the spectral ratio among the superficial receivers and the reference total wavefield at the cyclic model).

\section{Results from 1D numerical models}

The 1D numerical models performed on the 48 soil columns by the use of EERA (equivalent linear) and SWAP_3C (nonlinear) codes pointed out that the first mode of resonance for all the columns is close to $1 \mathrm{~Hz}$ with $\mathrm{A}(\mathrm{f})$ values generally almost equal to 2 . In several cases, depending on specific stratigraphical situations, other modes of resonance result at frequencies varying from 2 up to $5 \mathrm{~Hz}$ with $\mathrm{A}(\mathrm{f})$ values up to 5 , as in the case of the columns $11 \mathrm{D}, 11 \mathrm{E}$ and $5 B$.

The MSS computed through the nonlinear model (SWAP_3C) represents the octahedral shear strain; it takes into account the effects due to the 3D rheology and is generally higher than the 
MSS computed through the equivalent linear model (EERA), see (Fig.8). Nevertheless this result depends at the same time on the various rheologies (equivalent linear and cyclic nonlinear) and on the number of components of the seismic input (i.e. 3 components for SWAP and 1 component for EERA). To evidence the role of the cyclic nonlinear rheology with respect to the equivalent linear one, a comparison of the computed MSS by EERA and SWAP considering one input component only is displayed in Fig. 8. As it results from this comparison, the MSS computed by SWAP generally exceed the ones computed by EERA.

The MSS resulting for the $\mathrm{C}$ layers are always higher than the ones measured in the other soil layers; moreover, they result more concentrated where the $\mathrm{C}$ layer is thinner, i.e. it results boxed within stiffer layers such as D1, B and G. Based on these outputs and considering the largest presence of the $\mathrm{C}$ layer when compared to the other ones within the alluvial deposits, this study was mostly focused on the behaviour of such a clayey layer within the alluvial fill. By analysing the MSS distribution along each selected soil column and within the $\mathrm{C}$ layers it results that: i) the highest values are generally located at the bottom of the layer (Fig.8), ii) the MSS increase with decreasing $\mathrm{C}$ layer thickness at the same depth (compare columns 7C and 8E in Fig.8); iii) the MSS values increase with depth for the same thickness of the stratum (see columns 7B and 8E in Fig.8) and iv) the MSS generally exceed the $\gamma_{\mathrm{v}}$ of the C layer (Figs. 8, 9).

In particular, Fig.9 shows that the exceedance of the $\gamma_{\mathrm{v}}$ threshold (expressed through the MSS/ $\gamma_{v}$ ratio also considering the related standard deviation) is independent of the thickness of the $\mathrm{C}$ layer and the assumed rheology (i.e. EERA vs. SWAP)

These results highlight that both the layer thickness and the layer stratigraphical position along the soil column control the resulting MSS.

\section{Results from $2 D$ numerical models}

The $2 \mathrm{D}$ models along the 4 selected sections $(1,6,7$ and 11) confirmed that the $1 \mathrm{~Hz}$ frequency 
is amplified all along the models with $\mathrm{A}(\mathrm{f})$ values up to 4 (Figs.10,11,12,13); nevertheless significant amplifications result at higher frequencies (up to $8 \mathrm{~Hz}$ ). Along each section, 1D transfer functions were computed by discretizing the numerical domain in $5 \mathrm{~m}$-spaced soil columns and by assuming a viscoelastic rheological model; the so obtained A(f) values were reported in a unique plot as a function of the distance along the section (Figs.10b,11b,12b,13b). The computed $1 \mathrm{D} A(\mathrm{f})$ functions were compared with the $\mathrm{A}(\mathrm{f})$ functions obtained by the $2 \mathrm{D}$ viscoelastic modelling: such a comparison reveals a significant difference in the distribution of and vertically confined between stiffer deposits as for the MSS absolute values. 


\section{Discussion}

Numerical results are analyzed in order to point out the effect of both vertical and lateral heterogeneities on the computed MSS. At this aim, a differential scheme is herein proposed: it is based on evaluating the difference, compared to a reference value, in some specific parameters influencing the MSS within the soil deposits.

Three main contributions are considered: the vertical heterogeneity related to the layering of the soil layers; the stratigraphic position of the layer, i.e. the depth measured from the ground layer; the lateral heterogeneities due to the contacts among soil deposits with significant impedance contrast, including the lateral contacts between soil and bedrock due to the $2 \mathrm{D}$ geometry of the river valley.

As previously discussed the present analysis is focused on the C layer only.

A first index (Shear Strain Concentration Index - SSCI) was introduced to quantify the concentration of MSS within the C layer in the form:

$$
S S C I=\frac{\Delta \gamma}{\Delta h}=\frac{\left(\gamma_{\max }-\gamma_{\min }\right)}{h_{\max }-h_{\min }}
$$

where:

$\gamma_{\max }$ is the maximum shear strain within the $\mathrm{C}$ layer in the considered column; $\gamma_{\min }$ is the minimum shear strain within the $\mathrm{C}$ layer in the considered column; $\left(h_{\max }-h_{\min }\right)$ is the difference between the two depths at which the minimum and maximum values of the shear strain are obtained within the $\mathrm{C}$ layer; this difference generally coincides with the thickness of the same layer (Fig. 15).

To subtract the effect due to the stratigraphic position of the layer (i.e. to its depth b.g.l.) the same index was computed for homogeneous reference columns only constituted by sands or clays over a stiff gravel layer representing the seismic bedrock. Eighteen reference columns were constructed by considering 2 soil compositions (sandy and clayey) and 9 thicknesses (i.e. 
varying from 50 up to $70 \mathrm{~m}$ ) to be representative for the different cases encountered in the 48 modeled soil columns.

457 A differential index was defined in the form:

where SSCI is the shear strain concentration index for the C layer in each considered column and the $S S C I_{r e f}$ is the one defined for the specific reference column.

The $\Delta \Gamma$ index reveals the effect due to vertical heterogeneity only, by excluding the effect due to the depth of the layer in the soil column; as it is shown by the graphs in Fig.16 a good values corresponding to the outputs of the soil columns characterized by the same thickness of the C layer. Such a correlation results for both the EERA and the SWAP_3C models (Fig.16a,b) and demonstrates that as the soil column heterogeneity increases (i.e. the $\mathrm{C}$ layer thickness is lower than $10 \mathrm{~m}$ which corresponds to almost $20 \%$ of the entire soil column) the average $\Delta \Gamma$ increases as well as the related standard deviation. As it results from these outputs, at an increasing vertical heterogeneity of the soil column corresponds a lower reliability of the shear strain prevision within the $\mathrm{C}$ layer, as it is strongly affected by the soil column stratigraphy, i.e. by the soil layering.

A similar analysis was carried out for the 2D modeling (Fig.16c); also in this case, the effect due to the vertical heterogeneity was analyzed by using the $\Delta \Gamma$ index. At this aim, 17 soil columns were extracted from the 4 modeled cross sections in correspondence to the same soil columns among the 48 considered ones, that are distributed along these sections. Also in this case, a good correlation exists between the thickness of the $\mathrm{C}$ layer and the $\Delta \Gamma$ computed averaging all values corresponding to the outputs of soil columns extracted along the sections and characterized by the same C layer thickness. Similarly to results obtained by the 1D models, the resulting $\Delta \Gamma$ distribution shows that the reliability of the shear strain prevision within the $\mathrm{C}$ 
layer is strongly affected by the soil column stratigraphy as the computed standard deviation has a very sharp increase in the cases of $\mathrm{C}$ layer thickness lower than $10 \mathrm{~m}$. In order to evaluate the effects of the horizontal heterogeneities, i.e. due to the lateral contacts among the soil layers as well as between the soil deposit and the bedrock, another differential index was introduced by subtracting the $\Delta \Gamma$ from $1 \mathrm{D}$ to the one from $2 \mathrm{D}$ model in the form:

$\Delta \Gamma_{1 \mathrm{D} \_2 \mathrm{D}}=\left|\Delta \Gamma_{1 \mathrm{D}}-\Delta \Gamma_{2 \mathrm{D}}\right|$

As $\Delta \Gamma$ already subtracts the effect due to the stratigraphic position of the $\mathrm{C}$ layer with respect to its depth in the soil column, the $\Delta \Gamma_{1 \mathrm{D}_{2} 2 \mathrm{D}}$ index only takes into account the role of lateral heterogeneities in the computed MSS. To allow a comparison with the $2 \mathrm{D}$ modeling results and to better constrain the results expressed by $\Delta \Gamma_{1 D_{-} 2 \mathrm{D}}$ index, the $\Delta \Gamma_{1 \mathrm{D}}$ was computed from the $1 \mathrm{D}$ models performed by the SWAP_3C code but using one ground motion component only. A sensitivity analysis was performed by correlating the $\Delta \Gamma_{1 D_{-} 2 \mathrm{D}}$ values and the distance $(\Delta \mathrm{X})$ measured from each considered column to the closest lateral contact due to heterogeneities which are characterized by a $\Delta \mathrm{Vs}>200 \mathrm{~m} / \mathrm{s}$, these last ones including the basin seismic bedrock (Bard and Bouchon, 1985; Semblat et al., 2010). The obtained $\Delta \Gamma_{1 D_{-} 2 \mathrm{D}}$ vs. $\Delta \mathrm{X}$ distribution demonstrates that the $\Delta \Gamma_{1 \mathrm{D}_{-} 2 \mathrm{D}}$ index is suitable for revealing the effect of lateral heterogeneities since its value significantly increases for decreasing distances between the soil column and the closest lateral contact. In particular, for distances lower than $300 \mathrm{~m}$ the $\Delta \Gamma_{1 \mathrm{D}_{-} 2 \mathrm{D}}$ value sharply increases from 0.005 up to about 0.025 according to an exponential correlation function (Fig. 17a). A similar analysis was carried out by searching a correlation among the $\Delta \Gamma_{1 D_{-} 2 \mathrm{D}}$ index and the angle of inclination of the buried slopes at the basin edges (i.e. measured from the ground surface to the top of the G layer which represents the local seismic bedrock) (Fig. 17b). In this case, the outputs only show a decreasing trend of $\Delta \Gamma_{1 D_{-} 2 \mathrm{D}}$ values with increasing slope angle; nevertheless, a proper correlation does not result and also for small slope angle $\left(<10^{\circ}\right)$ the $\Delta \Gamma_{1 D_{-} 2 \mathrm{D}}$ values are not negligible. These results demonstrate the main role played by lateral 
heterogeneities with respect to the slope angle in the MSS concentration within the clay C layer of the Tiber River alluvia at Rome historical center. They also highlight the relevance of 2D models in case of lateral heterogeneities, where the lateral contacts are closer than $300 \mathrm{~m}$ from 508 
heterogeneities due to high-impedance contrast are localized at a distance higher than $300 \mathrm{~m}$ (Bozzano et al., 2008), i.e. in agreement with the correlation reported in Fig.17a the expected $\Delta \Gamma_{1 D_{-} 2 \mathrm{D}}$ value is indeed suitable to a $1 \mathrm{D}$ strain effect.

It is worth noticing that, as it results from both the $1 \mathrm{D}$ and the $2 \mathrm{D}$ numerical models, the MSS $/ \gamma_{\mathrm{v}}$ ratio distributions indicate that in several cases the $\gamma_{\mathrm{v}}$ threshold is exceeded more than one order of magnitude. Although the shaking conditions considered herein correspond to a very severe earthquake scenario for the city of Rome (i.e. the computed MSS are the maximum expected for a $10 \%$ of PGA exceedance in 50 years), a kind of criticism remains in the relevancy of the dynamic parameters resulting from resonant column tests (that generally provide the available dynamic parameters used for numerical modeling as in this study). This is particularly true under strictly nonlinear conditions (i.e. by considering strong motion effects), that imply a significant increase of the pore water pressures, and in case of heterogeneous deposits which not necessarily respect plane-parallel layering conditions. Another source of uncertainty is the variability of the reference input ground motion which could be addressed by further details in a more specific study.

\section{Conclusions}

This study was focused on the effects of earthquake shaking on shear strains by taking into account the effect of vertical and lateral heterogeneities due to the contacts among different soils within an alluvial fill deposit.

At this aim, the Rome historical center was selected as case study since a detailed 3D engineering-geology model of the subsoil is already available and a significant exposure exists due to the intense urbanization and to the monumental historical heritage of the area.

1D and 2D numerical models were focused on the evaluation of MSS within the clayey deposits 
(i.e. ascribable to the lithotechnical layer C) which constitute the most part of the alluvial fill. Nonetheless, a kind of criticism remains on the suitability of properties derived from resonant column laboratory tests in case of high-strain level and heterogeneous soil conditions as the present results generally show a significant exceedance of the volume shear strain threshold $\gamma_{\mathrm{v}}$ in all the performed models.

To distinguish the effect due to both vertical heterogeneities (i.e. to the strata layering) and lateral heterogeneities, some specific indexes were defined. The SSCI index expresses the shear strain concentration within a specific layer of each soil column. The $\Delta \Gamma$ index subtracts the effect of the stratigraphic position of the considered soil layer since it compares the effect of a multilayered column with the one obtained along a homogeneous reference one. Finally, the $\Delta \Gamma_{1 \mathrm{D} \_2 \mathrm{D}}$ evidences the effect due to the lateral heterogeneities; the responsiveness of this index to the distance of a soil column from the closest lateral contact with a high impedance contrast demonstrated its reliability and pointed out the dependence of the soil column position along a specific cross section to assume 2D or 1D conditions for numerically computing the expected MSS.

The $\Delta \Gamma_{1 \mathrm{D} \_2 \mathrm{D}}$ was used for a zonation of the MSS in clay layer $\mathrm{C}$ of Rome historical center in terms of suitable areas for 1D or 2D numerical models. The present approach also provides useful indications for selecting the most suitable numerical approaches in the frame of seismic microzonation studies that, for the specific case of Rome, were not yet carried out.

This study shows the relevance of 2D models to provide expected values of MSS in case of soil deposits characterized by lateral heterogeneities; the obtained findings also point out that the role of heterogeneities is more relevant with respect to the shape of the valley bedrock, since the numerically computed MSS correlates well with the distance to the lateral contact while, conversely, no significant correlation exists with the angle of inclination of the buried slopes.

These obtained results encourage to improve the quality of the MSS evaluation within soil deposits under severe earthquake scenarios in urban areas, as they can interact with structure 
foundations or infrastructures.

\section{Data and Resources}

The web-site of the Italian national project UHS INGV, Central Italy was visited at the web-site http://esse1.mi.ingv.it/ (last accessed December 2013). For selecting the reference input the

European Strong-motion Database (ESD) was visited at the web-site http://www.isesd.hi.is/ESD_Local/frameset.htm (last accessed July 2012).

\section{Acknowledgements}

This study was carried out on in the frame of a PhD research funded by the Department of Earth Sciences of the University of Rome "La Sapienza" in co-operation with the IFSTTAR of Paris.

The research was also part of the SERIES EUROPEAN PROJECT: "Experimental and Numerical Investigations of Nonlinearity in soils using Advanced Laboratory-Scaled models (ENINALS)" (co-ordinator G. Scarascia Mugnozza, TA Use Agreement signed on 3 March 2010 in the frame of the "Grant Agreement No. 227887" of the "European Commission, 7th Framework Program). The Authors wish to thank G. Martini of the ENEA Italian Agency for the contribution given to the obtain the 3 component input for the numerical modeling; J.L. Tacita and L. Stedile for the technical support in the laboratory tests.

\section{References}

602

Assimaki, D., Gazetas, G., and E. Kausel (2005). Effects of Local Soil Conditions on the Topographic Aggravation of Seismic Motion: Parametric Investigation and Recorded Field Evidence from the 1999 Athens Earthquake, Bul Seism Soc Am, 95(3), 1059-1089.

Athanasopoulos, G.A., Pelekis, P.C., and E.A. Leonidou (1999). Effects of surface topography on seismic ground response in the Egion (Greece) 15 June 1995 earthquake, Soil Dynamics and 
608 Bakavoli, M.K., and E. Hagshenhas (2010). Experimental and numerical study of topographic site 609 effect on a hill near Tehran, Proc. Fifth International Conference of Recent Advances in 610 Geotechnical Earthquake Engineering and Soil Dynamics (May 24-29, S.Diego - California), $1-9$.

Amato, A., Chiarabba, C., Cocco M., di Bona M., and M. G. Selvaggi (1994). The 1989- 1990 seismic swarm in the Alban Hills volcanic area, central Italy, J. Volcanol. Geotherm. Res., 61, $225-237$.

Ambrosini, S., Castenetto, S., Cevolan, F., Di Loreto, E., Funiciello, R., Liperi, L. and D. Molin (1986). Risposta sismica dell'area urbana di Roma in occasione del terremoto del Fucino del 13 Gennaio 1915, Memorie della Società Geologica Italiana, 35, 445-452.

Assimaki, D., and W. Li (2012). Site and ground motion-dependent nonlinear effects in seismological model predictions. Soil Dynamics and Earthquake Engineering, 32, 143-151.

Bard P.Y. and M. Bouchon (1980a). The seismic response of sediment-filled valleys. Part I. The case of incident SH waves, Bull. Seism. Soc. Am., 70, 1263-1286.

Bard P.Y. and M. Bouchon (1980b). The seismic response of sediment-filled valleys. Part II. The case of incident P and SV waves, Bull. Seism. Soc. Am., 70, 1921-1941.

Bard, P.Y. and M. Bouchon (1985). The two-dimensional resonance of sediment-filled valleys, Bull. Seism. Soc. Am., 75, 519 - 541.

Bardet, J. P., Ichii, K., and C. H. Lin (2000). EERA: a computer program for equivalent-linear earthquake site response analyses of layered soil deposits, Report University of Southern California, Department of Civil Engineering.

Bardet, J. P., and T. Tobita (2001). NERA: A Computer Program for Nonlinear Earthquake Site Response Analyses of Layered Soil Deposits, 
Blumetti, A.M., Comerci, V., Di Manna, P., Guerrieri, L., and E. Vittori (2009). Geological effects induced by the L'Aquila earthquake (6 April 2009, Ml=5.8) on the natural environment, iSPra Dipartimento Difesa del Suolo - Servizio geologico d'italia, preliminary report, 38.

Bonilla, F., Gélis, C., Giacomi, A.C, Lenti, L., Martino, S. and J.F. Semblat (2010). Multidisciplinary study of seismic amplification in the historical center of Rome, Italy, Proc. 5th Int. Conf. on Recent Advances in Geotech. Earthq. Engin. and Soil Dynamics, May 24-29 2010, San Diego, California.

Bonilla, L.F., Tsuda, K., Pulido, N., Regnier, J. and A. Laurendeau (2011). Nonlinear site response evidence of K-net and KiK-net records from the Mw 9 Tohoku earthquake. Earth Planets Space, 58, 785-789.

Bonilla, L. F., Liu, P. C., and S. Nielsen (2006). 1D and 2D linear and nonlinear site response in the Grenoble area, Proc. 3rd Int. Symp. on the Effects of Surface Geology on Seismic Motion (ESG2006).

Borcherdt R. D. (1994). Estimates of site-dependent response spectra for design (methodology and justification), Earthq. Spectra, 10, 617-653.

Bouden-Romdhane N., Kham, M., Semblat, J.F. and P. Mechler, (2003). 1D and 2D response analysis vs experimental data from Tunis city. Beşinci Ulusal Deprem Mühendisliği Konferansı, 26-30 May1s 2003, Proc. 5th National Conference on Earthquake Engineering, 26-30 May 2003, Istanbul, Turkey, Paper No: AE-051.

Bozzano, F., Andreucci, A., Gaeta, M., Salucci, R. and C. Rosa (2000). A geological model of the buried Tiber River valley beneath the historical center of Rome, Bull. Eng. Geol. Env., 59, 1-21.

Bozzano, F., Bretschneider, A., Giacomi, A.C., Lenti, L., Martino, S., Scarascia Mugnozza, G., Stedile, L. and J.L. (2012). Undrained behaviour of the sandy-silty levels of the Tiber River 
alluvial deposits in Rome (Italy), Italian Journal of Engineering Geology and Environment, 2(2002), 47-61.

657 Bozzano, F., Caserta, A., Govoni, A., Marra, F. and S. Martino (2008). Static and dynamic 658 characterization of alluvial deposits in the Tiber River Valley: new data for assessing potential 659 ground motion in the city of Rome, Journal of Geophysical Research, 113, 1-21.

660 Bozzano, F., Funiciello, R., Gaeta, M., Marra, F., Rosa, C. and G. Valentini (1997). Recent alluvial 661 deposit in Rome (Italy): morpho-stratigrafic, mineralogical and geomechanical characterisation, 662 Proc. of the International Symposium of Egineering Geology and Environment, Publ 1, 1193 $663 \quad 1198$.

664 Bozzano, F., Giacomi, A.C., Martino, S. and Corpo Nazionale Vigili del Fuoco (2011). Scenario di 665 danneggiamento indotto nella città di Roma dalla sequenza sismica aquilana del 2009, Italian 666

Caserta, A., Boore, D. M., Rovelli, A., Govoni, A., Marra, F., Della Monica, G. and E. Boschi (2013). Ground Motions Recorded in Rome during the April 2009 L'Aquila Seismic Sequence: Site Response and Comparison with Ground Motion Predictions Based on a Global Dataset, Bull. Seism. Soc. Am., 103(3), 1860-1874.

Cipollari, P., Cosentino, D. and N. Perilli (1993). Analisi biostratigrafica dei depositi terrigeni a ridosso della linea Olevano-Antrodoco, Geologica Romana, 29, 495-513.

Corazza, A., Lanzini, M., Rosa, C. and R. Salucci (1999). Caratteri stratigrafici, idrogeologici e geotecnici delle alluvioni tiberine del settore del centro storico di Roma, Il Quaternario, 12, 215-235. 
Di Giulio, G., Improta, L. , Calderoni, G. and A. Rovelli (2008). A study of the seismic response of the A.city of Benevento (Southern Italy) through a combined analysis of seismological and geological data. Engineering Geology, 97, 146-170.

Donati, S., Cifelli, F. and F. Funiciello (2008). Indagini macrosismiche ad alta densità per lo studio del risentimento sismico nella città di Roma, Memorie Descrittive Carta Geologica d'Italia, $\mathbf{8 0 ,}$ 3-13.

Donati, S., Funiciello, R. and A. Rovelli (1999). Seismic response in archaeological areas: the Case-History of Rome, Jour. Appl. Geophys., 41, 229239.

Fäh, D., C. Iodice, P. Suhadolc, and G. F. Panza (1993). A new method for the realistic estimation of seismic ground motion in megacities: The Case of Rome, Earthquake Spectra, 9, 643-668.

Gélis C., and L.F. Bonilla (2012). 2D P-SV numerical study of soil-source interaction in a nonlinear basin, Geophys. J. Int., 191, 1374-1390.

Gélis, C. and L.F. Bonilla (2014). Influence of a sedimentary basin infilling description of the 2D PSV wave propagation using linear and nonlinear constitutive models, Geophys. J. Int.,198, 1684-1700.

Gélis, C., Leparoux, D., Virieux, J., Bitri, A., Operto, S. And G. Grandjean G. (2005). Numerical modeling of surface waves over shallow cavities, Journal of Environmental \& Engineering Geophysics, 10(2), 111-121.

Iai, S., Matsunaga, Y., and T. Kameoka (1990-a). Strain space plasticity model for cyclic mobility, Report of the Port and harbour Research Institute, 29(4).

Iai, S., Matsunaga, Y. and T. Kameoka (1990-b). Parameter identification for a cyclic mobility model. Report of the Port and harbour Research Institute, 29(4), 57-83.

Iwan, W. D. (1967). On a class of models for the yielding behavior of continuous and composite systems. Journal of Applied Mechanics, 34, 612. 
Joyner A. L., Kornberg T., Coleman K. G., Cox D. R., and G. R. Martin (1985). Expression during embryogenesis of a mouse gene with sequence homology to the Drosophila engrailed gene, Cell, 43(1), 29-37.

Joyner, W. B. and A. T. Chen (1975). Calculation of nonlinear ground response in earthquakes. Bull. Seism. Soc. Am., 65(5), 1315-1336.

Kham, M., Semblat, J.F., Bard, P.Y., and P. Dangla (2006). Seismic site-city interaction: main governing phenomena through simplified numericla models. Bull. Seism. Soc. Am., 96(5), 1934-1951.

Karner D.B. and F. Marra (1998). Correlation of Fluviodeltaic Aggradational Sections with Glacial Climate History: A Revision of the Classical Pleistocene Stratigraphy of Rome, Geol. Soc. Am. Bull., 110, 748-758.

Karner, D.B. and Renne P.R. (1998). 40Ar/39Ar Geochronology of Roman Volcanic Province Tephra in the Tiber River Valley: Age Calibration of Middle Pleistocene Sea-Level Changes, Bull. Seis. Soc. Am., 110, 740-747.

Konder, R.L. and Zelasko J.S. (1963). A hyperbolic stress-strain formulation for sands, Proc. of 2nd Pan American Conference on Soil Mechanics and Foundation Engineering, Brazil, 289-324.

Lanzo, G. and F. Silvestri (1999). Risposta sismica locale: teoria ed esperienze, Hevelius (Editors), pp. 159.

Lenti, L., Martino, S., Paciello, A., and G.S. Mugnozza (2009). Evidence of two-dimensional amplification effects in an alluvial valley (Valnerina, Italy) from velocimetric records and numerical models, Bull. Seis. Soc. Am., 99(3), 1612-1635.

Semblat, J.F., Lokmane, N., Driad-Lebeau, L., and G. Bonnet (2010). Local amplification of deep mining induced vibrations part.2: simulation of ground motion in a coal basin. Soil Dynamics and Earthquake Engineering, 30, 947-957. 
Makra, K., Chávez-García, F. J., Raptakis, D. and K. Pitilakis (2005). Parametric analysis of the seismic response of a 2D sedimentary valley: implications for code implementations of complex site effects, Soil Dynamics and Earthquake Engineering, 25(4), 303-315.

Mancini, M., Moscatelli, M., Stigliano, F., Cavinato, G. P., Marini, M., Pagliaroli, A. and M. Simionato (2013). Fluvial facies and stratigraphic architecture of Middle Pleistocene incised valleys from the subsoil of Rome (Italy), Journal of Mediterranean Earth Sciences, Special Issue, 89-93.

Marra, F., Florindo, F. and D.B. Karner (1998). Paleomagnetism and geochronology of early Middle Pleistocene depositional sequences near Rome: comparison with the deep sea $\delta 180$ climate record, Earth and Planetary Science Letters, 159, 147-164.

Marra, F., Rosa C., De Rita, D. and R. Funiciello (1998). Stratigraphic and tectonic features of the middle Pleistocene sedimentary and volcanic deposits in the area of Rome (Italy), Quaternary International, 47-48, 51-63.

Milli, S., D’Ambrogi, C., Bellotti, P., Calderoni, G., Carboni, M.G., Celant, A., Di Bella, L., Di Rita, F., Frezza, V., Magri, D., Pichezzi, R.M. and V. Ricci (2013). The transition from wavedominated estuary to wave-dominated delta: The Late Quaternary stratigraphic architecture of Tiber River deltaic succession (Italy), Sedimentary Geology, 284-285, 159-180.

Molin, D., and E. Guidoboni (1989). Effetto fonti effetto monumenti a Roma: i terremoti dall'antichità ad oggi, "I terremoti prima del mille in Italia e nell'Area mediterranea", Ed. E. Guidoboni, Bologna, 194-223.

Mozco, P., and P. Y. Bard (1993). Wave diffraction, amplification and differential motion near strong lateral discontinuities, Bull. Seismol. Soc. Am., 83(1), 85-106.

Olsen K. B., Akinci A., Rovelli A., Marra F., and L. Malagnini (2006). 3D ground-motion estimation in Rome, Italy, Bull. Seismol. Soc. Am., 96(1), 133-146. 
Panza, G.F., Alvarez, L., Aoudia, A., Ayadi, A., Benhallou, H., Benouar, D., Bus, Z., Chen, Y., Cioflan, C, Ding, Z., El-Sayed, A., Garcia, J., Garofalo, B., Gorshkov, A., Gribovszki, K., Harbi, A., Hatzidimitriou, P., Herak, M., Kouteva, M., Kuzntzov, I., Lokmer, I., Maouche, S., Marmureanu, G., Matova, M., Natale, M., Nunziata, C., Parvez, I., Pasckaleva, I., Pico, R., Radulian, M., Romanelli, F., Soloviev, A., Suhadolc, P., Szeidovitz, G., Triantafyllidis, P., and F. Vaccari (2004). Realistic modeling of seismic input for megacities and large urban areas, $J$. Tech. Environ. Geol., 1, 6-42.

Pergalani, F., Compagnoni, M. and V. Petrini, V. (2008). Evaluation of site effects using numerical analyses in Celano (Italy) finalized to seismic risk assessment, Soil Dynamics and Earthquake Engineering, 28(12), 964-977.

Pergalani, F., Romeo, R., Luzi, L., Petrini, V., Pugliese, A. And T. Sanò,T. (1999). Seismic microzoning of the area struck by Umbria-Marche (Central Italy) Ms 5.9 earthquake of 26 September 1997, Soil Dynamics and Earthquake Engineering, 18(4), 279-296.

Peyrusse F., Glinsky N., Gelis C. and S. Lanteri (2014). A nodal discontinuous Galerkin method for site effects assessment in viscoelastic media - verification and validation in the Nice basin. Geophys. J. Int., 199, 315-334

Raspa, G., Moscatelli, M., Stigliano, F., Patera, A., Marconi, F., Folle, D., Vallone, R., Mancini, M., Cavinato, G. P., Milli, S., Coimbra, J.F. and L. Costa (2008). Geotechnical characterization of the upper Pleistocene-Holocene alluvial deposits of Roma (Italy) by means of multivariate geostatistics: Cross-validation results, Engineering Geology, 101, 251-268.

Rassem, M., Ghobarah, A. and C. Heidebrecht (1997). Engineering perspective for the seismic site response of alluvial valleys, Earthq. Eng. Struct. Dyn., 26, 477-493.

Régnier, J., Cadet, H., Bonilla L.F., Bertrand, E., and J.F. Semblat (2013). Assessing nonlinear behavior of soils in seismic site response. statistical analysis on KiK-net strong-motion data. Bull. Seismol. Soc. Am., 103(3), 1750-1770. 
Rovelli, A., Caserta, A., L. Malagnini, and F. Marra (1994). Assessment of potential strong motions in the city of Rome, Annali di Geofisica, 37, 1745-1769.

Rovelli, A., Malagnini, L., Caserta, A. and F. Marra (1995). Using 1-D and 2-D modeling of ground motion for seismic zonation criteria: results for the city of Rome, Annali di Geofisica, 38(5-6), $591-605$.

Saenger, E. H., Gold, N. and S. A. Shapiro (2000). Modeling the propagation of elastic waves using a modified finite-difference grid, Wave motion, 31(1), 77-92.

Santisi d'Avila, M. P., Lenti, L., and J.F. Semblat (2012). Modeling strong seismic ground motion: three-dimensional loading path versus wavefield polarization, Geophysical Journal International, 190(3), 1607-1624.

Santisi d'Avila, M. P., Semblat, J. F. and L. Lenti (2013). Strong Ground Motion in the 2011 Tohoku Earthquake: A One-Directional Three-Component Modeling, Bull. Seismol. Soc. Am., 103, 1394-1410.

Segalman, D. J. and M. J. Starr (2008). Inversion of Masing models via continuous Iwan systems, International Journal of Non-Linear Mechanics, 43(1), 74-80.

Semblat, J. F., Dangla, P., Kham, M. and A. M. Duval (2002-a). Seismic site effects for shallow and deep alluvial basins: in-depth motion and focusing effect, Soil Dynamics and Earthquake Engineering, 22(9), 849-854.

Semblat, J.F., Duval, A.M. and P. Dangla (2000). Numerical analysis of seismic wave amplification in Nice (France) and comparisons with experiments, Soil Dyn. Earthq. Eng., 19(5), 347-62.

Semblat, J. F., Duval, A.M. and P. Dangla (2002-b). Seismic site effects in a deep alluvial basin: numerical analysis by the boundary element method, Computers and Geotechnics, 29(7), 573585.

Semblat, J.F., Kham, M., Parara, E., Bard, P.Y., Pitilakis, K., Makra, K. and D. Raptakis (2005). 
800

801

802

803

804

805

806

807

808

809

810

Site effects: basin geometry vs soil layering, Soil Dynamics and Earthquake Engineering, 25(710), 529-538.

Semblat, J.F., Kham, M., and P.Y. Bard (2008). Seismic-wave propagation in alluvial basins and influence of site-city interaction. Bull. Seismol. Soc. Am., 98(6), 2665-2678.

Semblat, J.F. and A. Pecker (2009). Waves and vibrations in soils: Earthquake, traffic, shocks, construction works, IUSS Press, ISBN: 8861980309, 499 pp.

Sørensen, M.B., Oprsal, I., Bonnefoy-Claudet, S., Atakan, K., Mai, P. M., Pulido, N. and C. Yalciner (2006). Local site effects in Ataköy, Istanbul, Turkey, due to a future large earthquake in the Marmara Sea, Geophysical Journal International, 167(3), 1413-1424.

Tertulliani, A., Tosi, P. and V. De Rubeis (1996). Local seismicity in Rome (Italy): recent results from macroseismic evidences, Annali di Geofisica, 39(6), 1235-1240.

Towhata I. and K. Ishiara (1985). Modeling Soil Behavior Under Principal Axes Rotation, Proc. 5th Fifth International Conference on Numerical Methods in Geomechanics, Nagoya, 523-530.

Virieux J. (1986). P-SV wave propagation in heterogeneous media: Velocity-stress finite-difference method, Geophysics, 51(4), 889-901. 


\section{Captions to figures}

834 Fig. 1 - a) Location of the city of Rome respect to the central Apennines (modified from Cipollari et 835 al., 1993) the : 1) alluvial and coastal deposits; 2) volcanic deposits; 3) terrigenous flysch deposits; 836 4) limestones; 5) main thrust; 6) main fault; 7) epicentral location of the 1915 Avezzano and of the 8372009 L'Aquila earthquakes. b) satellite GoogleEarth view the Rome historical center; the locations 838 of the considered soil columns and sections are also shown (the 2D modeled sections are indicated 839 by a circled number).

840 Fig. 2 - Borehole stratigraphic log showing the main lithotechnical units that were distinguished in 841 the Tiber River alluvial deposits at Rome historical center.

842 Fig.3 - a) Rheological and velocity model assumed for the subsoil of the Rome historical center, $(*)$ 843 dynamic properties available so far from specific laboratory tests; b) normalized shear modulus 
$844\left(\mathrm{G} / \mathrm{G}_{0}\right)$ and damping (D) vs. shear strain $(\gamma)$ used in the numerical models and referred to each 845 lithotechnical unit.

846 Fig.4 - a) 3D engineering-geology model of the alluvial fill in the Rome historical center; b) 847 example of geological cross section extracted from the 3D model and; c) smoothing of the 848 geological cross-section for the numerical models.

849 Fig.5 - Percentage distribution of the soil layers (a) and percentage distribution of the clayey C 850 layer thickness (b) within the here considered 48 soil columns of the Tiber River alluvial deposits at 851 Rome historical center.

852

853 854 855

Fig.6 - Reference 3-component input used for the numerical modeling (by Guido Martini, ENEA Italy): timehistories (left column) and Fast Fourier Transform (right column) of the horizontal (up and middle) and vertical (down) components of the input.

Fig.7 - Engineering-geological cross sections along the traces 1, 6, 7 and 11 (see Fig.1 for location) used for the performed 2D numerical models. The 17 soil columns considered for computing the $\Delta \Gamma_{1 D_{2} 2 \mathrm{D}}$ index are also shown (see also Fig.1 for location).

Fig.8 - MSS distribution along some of the 48 modeled soil columns (see Fig. 1 for location) by the codes EERA and SWAP; in the case of SWAP the MSS distribution for both the 1-component input (SWAP_1C) and for the 3-component input (SWAP_3C) are distinguished.

Fig.9 - Average MSS $/ \gamma_{v}$ vs. the C layer thickness distributions (+/- standard deviation, dashed lines) in the case of: a) EERA (1-component input); b) SWAP (3-component input). The labels close to the black circles indicate the number of cases considered for the mean.

Fig.10 - Outputs of the 2D numerical model performed along section 1 of Fig.7: a) Vs value distribution in the numerical domain; b) A(f) function from the $1 \mathrm{D}$ viscoelastic solution; c) $A(f)$ 
function from the 2D viscoelastic solution; d) A(f) function from the 2D viscoplastic solution. The A(f) functions are plotted for the basin width only.

Fig.11 - Outputs of the 2D numerical model performed along section 6 of Fig.7: a) Vs value distribution in the numerical domain; b) A(f) function from the $1 \mathrm{D}$ viscoelastic solution; c) $\mathrm{A}(\mathrm{f})$ function from the $2 \mathrm{D}$ viscoelastic solution; d) A(f) function from the $2 \mathrm{D}$ viscoplastic solution. The A(f) functions are plotted for the basin width only.

Fig.12 - Outputs of the 2D numerical model performed along section 7 of Fig.7: a) Vs value distribution in the numerical domain; b) A(f) function from the $1 \mathrm{D}$ viscoelastic solution; c) $\mathrm{A}(\mathrm{f})$ function from the 2D viscoelastic solution; d) A(f) function from the $2 \mathrm{D}$ viscoplastic solution. The A(f) functions are plotted for the basin width only.

Fig.13 - Outputs of the 2D numerical model performed along section 11 of Fig.7: a) Vs value distribution in the numerical domain; b) A(f) function from the $1 \mathrm{D}$ viscoelastic solution; c) $A(f)$ function from the 2D viscoelastic solution; d) A(f) function from the 2D viscoplastic solution. The A(f) functions are plotted for the basin width only.

Fig. $14-\mathrm{MSS} / \gamma_{\mathrm{v}}$ ratio distributions resulting by the 2D numerical models for section 1 (a), 6 (b), 7 (c) and $11(\mathrm{~d})$; the MSS distributions within the models are also reported.

Fig. 15 - Sketch that illustrates the $\Delta \Gamma$ index obtained by subtracting the SSCI index computed for the $\mathrm{C}$ layer in a general column to the same index computed for the corresponding reference column.

Fig.16 - $\Delta \Gamma$ index distributions vs. $C$ layer thickness as they result from the EERA, SWAP_3C (for a 3-component input) and 2D numerical models. The outputs are referred to the 48 soil columns of Fig. 1 for the 1D models and to the 17 soil columns of Fig. 7 for the $2 \mathrm{D}$ models. The labels close to the black circles indicate the number of cases considered for the mean. 
889 Fig, $17-$ a) $\Delta \Gamma_{1 D_{-} 2 \mathrm{D}}$ index distributions vs. the maximum distance of the $\mathrm{C}$ layer from the closest 890 high-impedance $(\Delta \mathrm{Vs}>200 \mathrm{~m} / \mathrm{s})$ lateral contact $(\Delta \mathrm{X})$ and b) $\Delta \Gamma_{1 \mathrm{D} \_2 \mathrm{D}}$ index distributions vs. the 891 inclination angles of the slope buried below the alluvial deposits in the Tiber River valley at Rome 892 historical center.

893 Fig.18 - GoogleEarth satellite view of the Rome historical center in which the Tiber River alluvial 894 deposits are bounded by a bold white lines and the zones suitable for 1D (areas with the white lines) 895 and 2D (areas without lines) shear strain effects are mapped; MSS values expected in the C layer 896 for the 475-years earthquake scenario are also reported.

898 Authors' mail list

899 salvatore.martino@uniroma1.it

900 luca.lenti@ifsttar.fr

901 celine.gelis@irsn.fr

902 chiaragiacomi@me.com

903 msantisi@unice.fr

904 fabian.bonilla@ifsttar.fr

905 francesca.bozzano@uniroma1.it

906 jean-francois.semblat@ifsttar.fr 
(a)

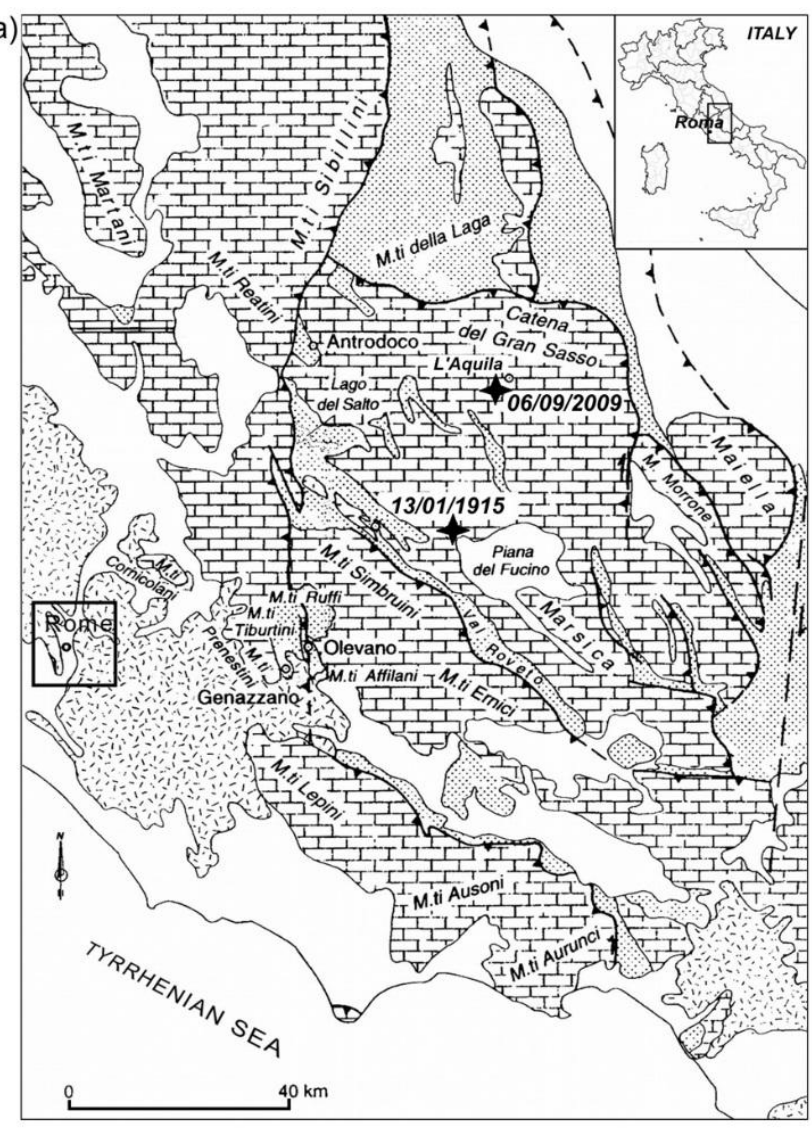

912 by a circled number).

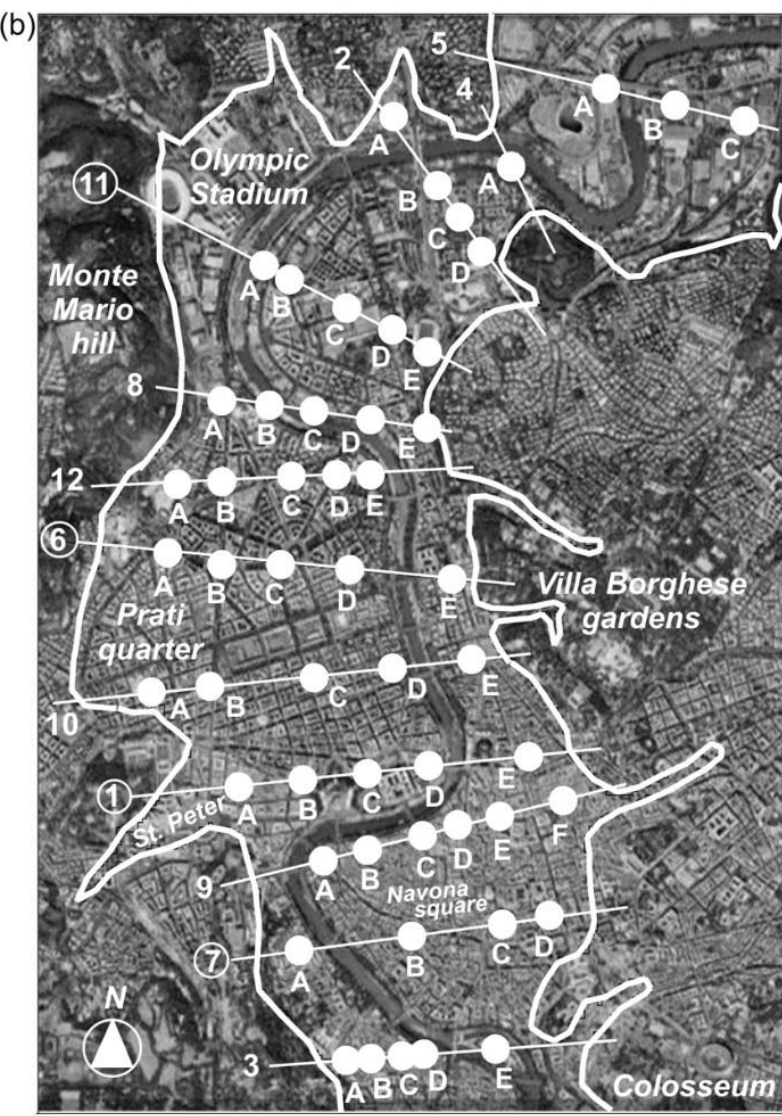

$\overline{0}-\overline{500} \quad{ }_{1000}^{m}$

Fig. 1 - a) Location of the city of Rome respect to the central Apennines (modified from Cipollari et al., 1993) the : 1) alluvial and coastal deposits; 2) volcanic deposits; 3) terrigenous flysch deposits; 4) limestones; 5) main thrust; 6) main fault; 7) epicentral location of the 1915 Avezzano and of the 2009 L'Aquila earthquakes. b) satellite GoogleEarth view the Rome historical center; the locations of the considered soil columns and sections are also shown (the 2D modeled sections are indicated 

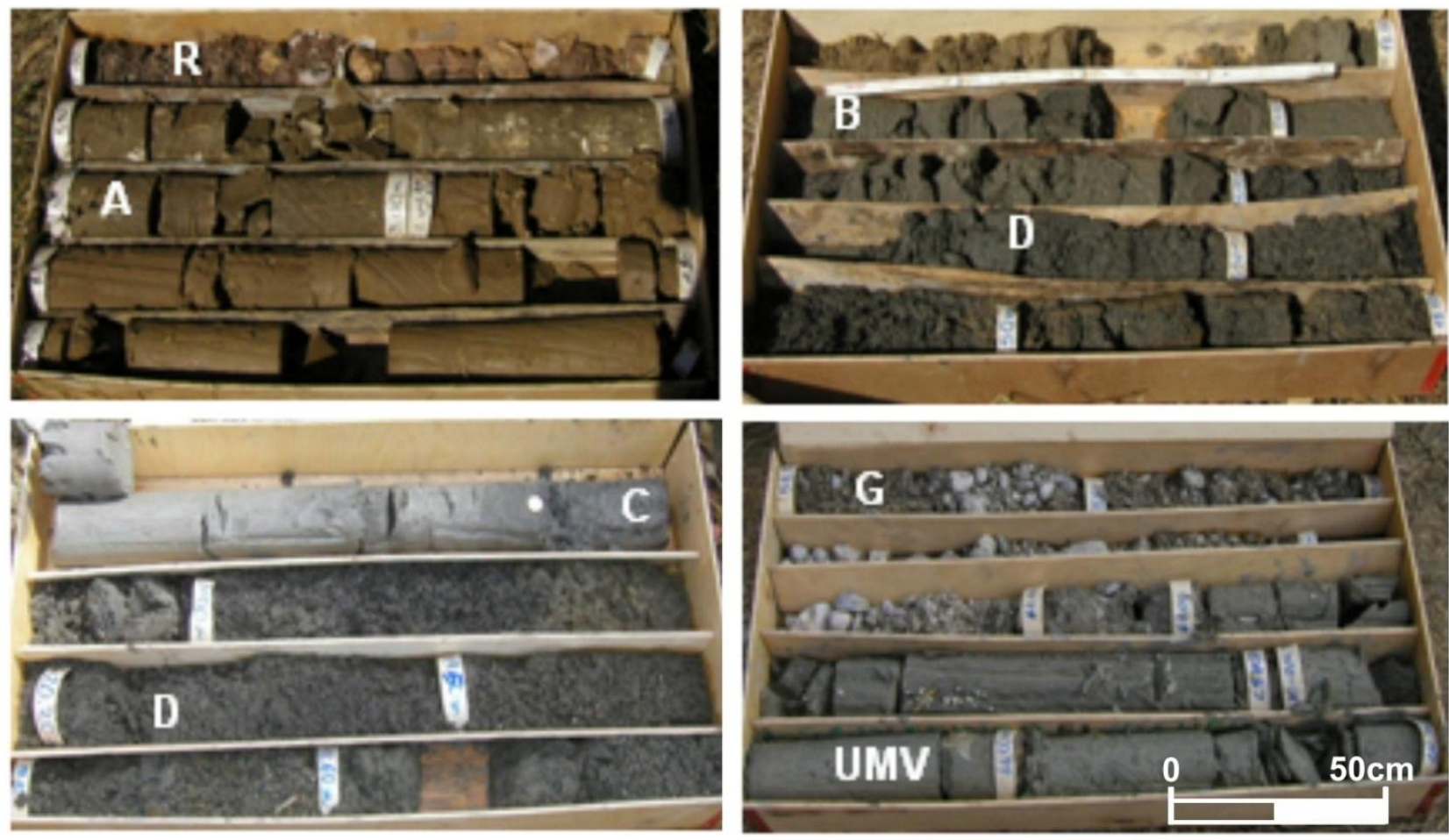

920 Fig. 2 - Borehole stratigraphic log showing the main lithotechnical units that were distinguished in 921 the Tiber River alluvial deposits at Rome historical center. 


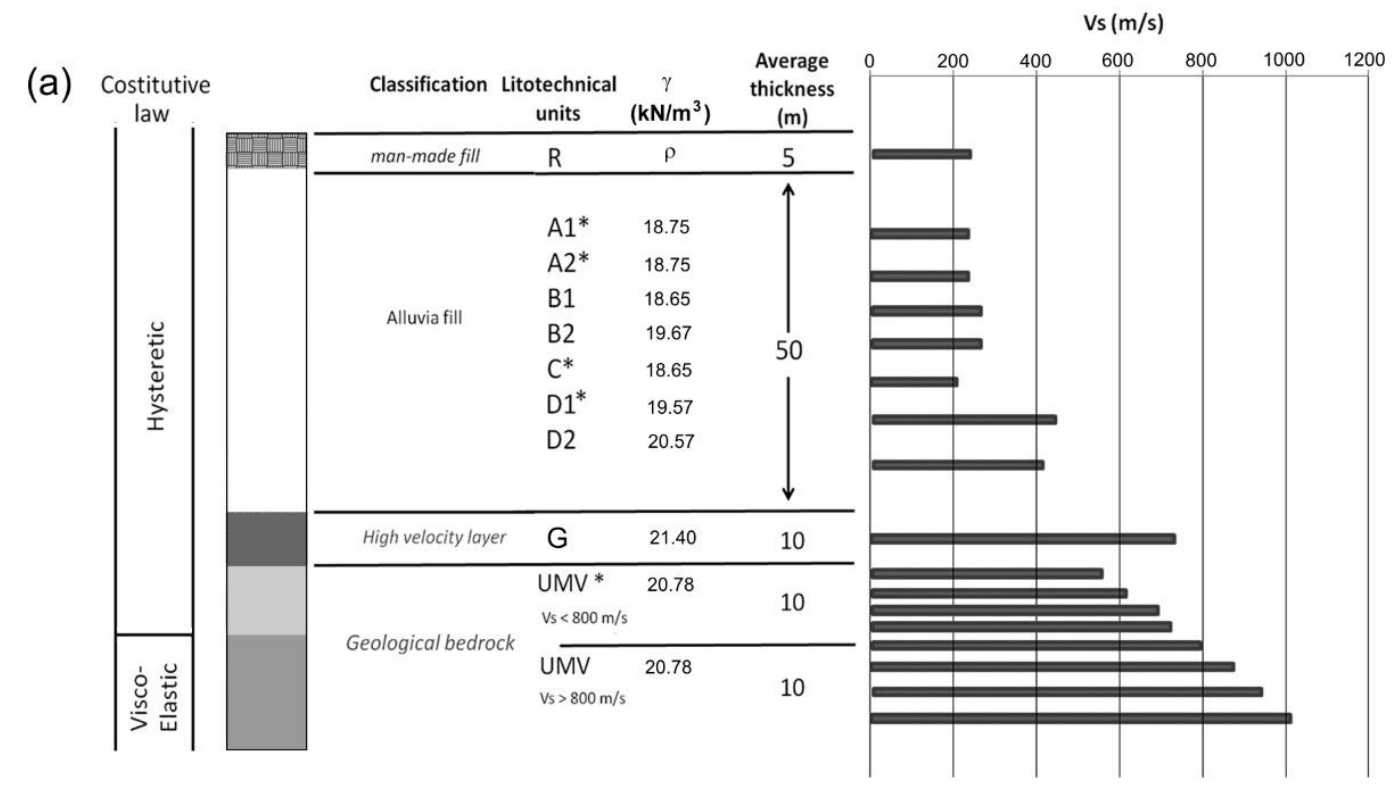
(b) $\quad \mathrm{G} / \mathrm{G}_{0}$
$\mathrm{D}(\%)$

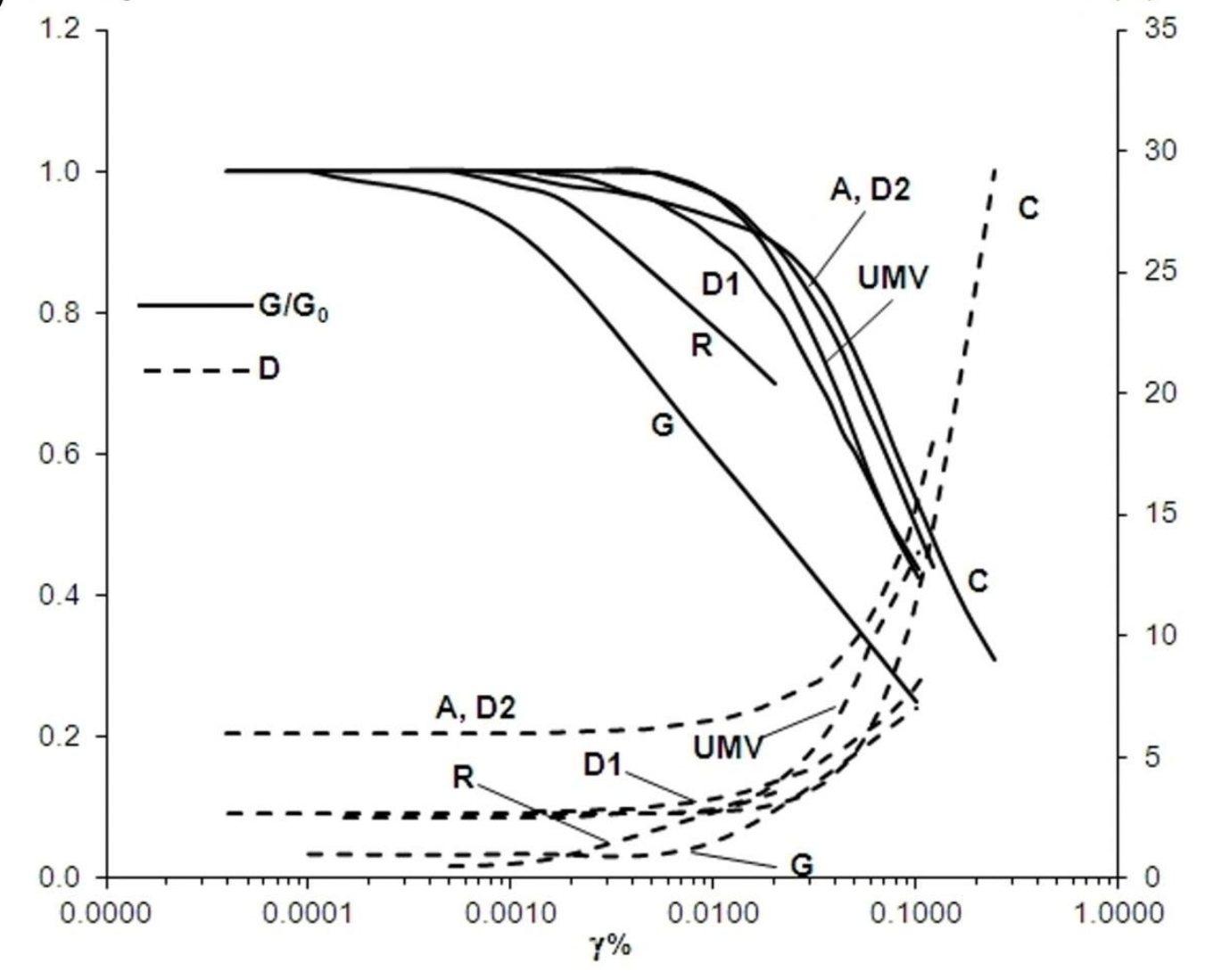

923 Fig.3 - a) Rheological and velocity model assumed for the subsoil of the Rome historical center, (*)

924 dynamic properties available so far from specific laboratory tests; b) normalized shear modulus $925\left(\mathrm{G} / \mathrm{G}_{0}\right)$ and damping (D) vs. shear strain $(\gamma)$ used in the numerical models and referred to each 926 lithotechnical unit. 

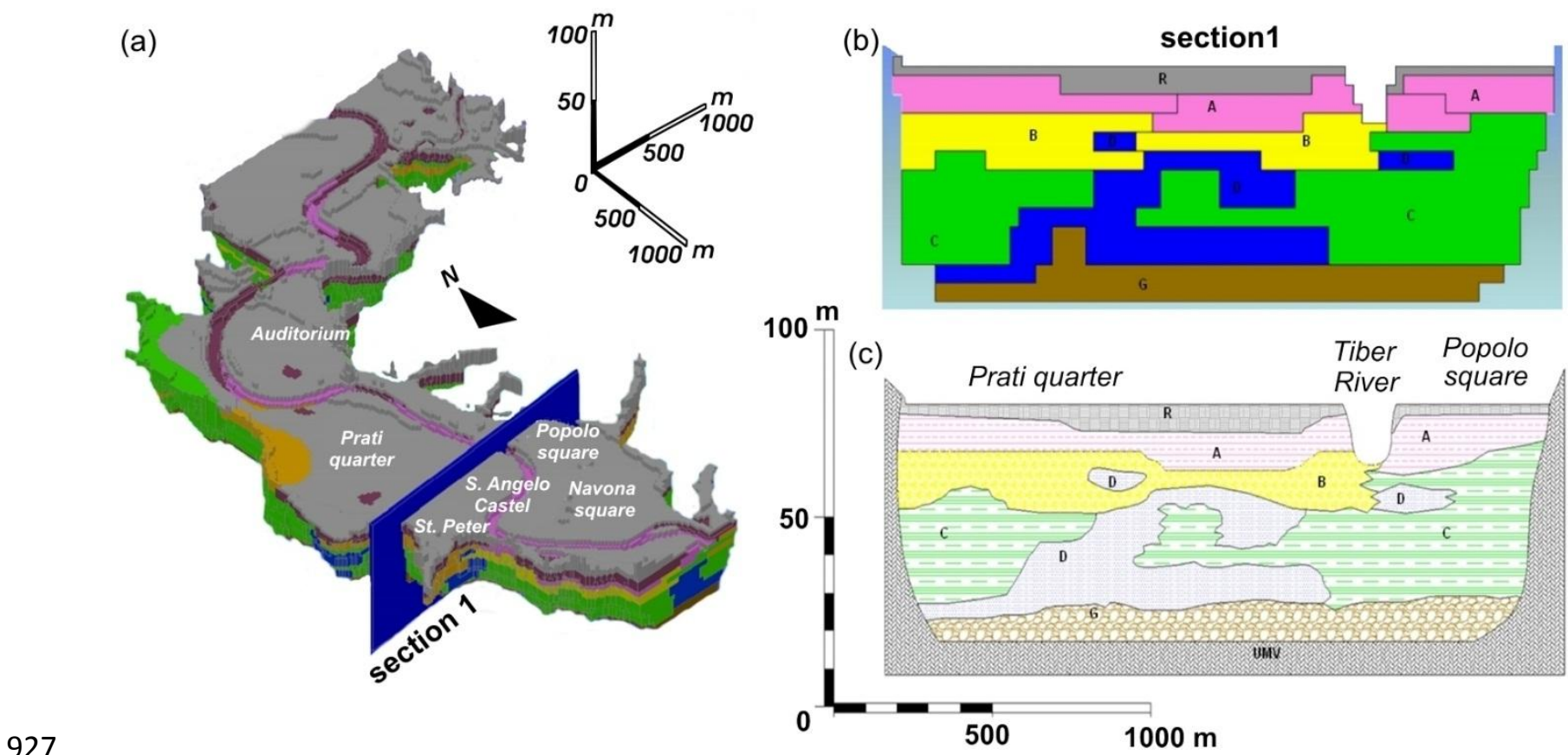

928 Fig.4 - a) 3D engineering-geology model of the alluvial fill in the Rome historical center; b) 929 example of geological cross section extracted from the 3D model and; c) smoothing of the 930 geological cross-section for the numerical models. 

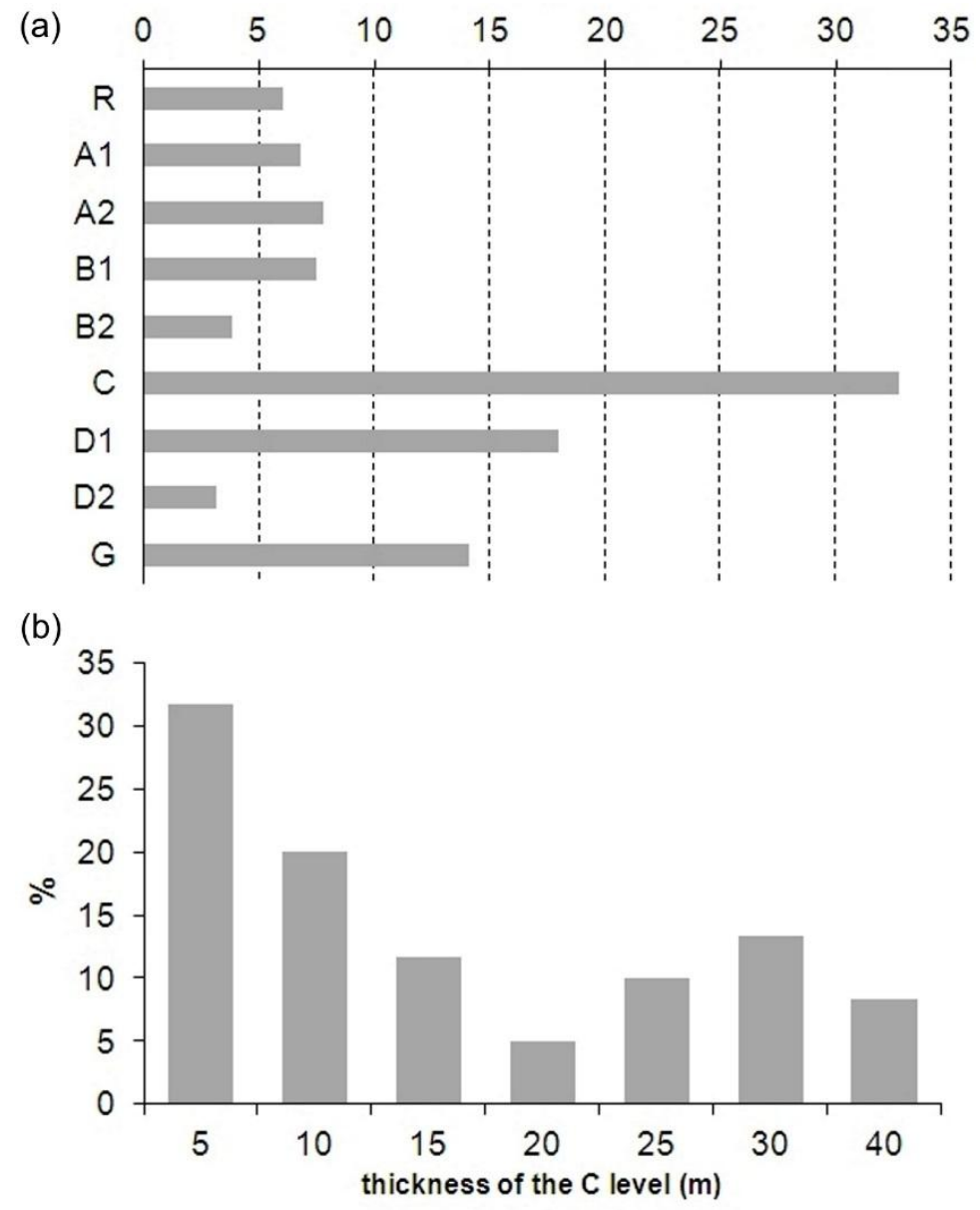

932 Fig.5 - Percentage distribution of the soil layers (a) and percentage distribution of the clayey C 933 layer thickness (b) within the here considered 48 soil columns of the Tiber River alluvial deposits at 934 Rome historical center. 

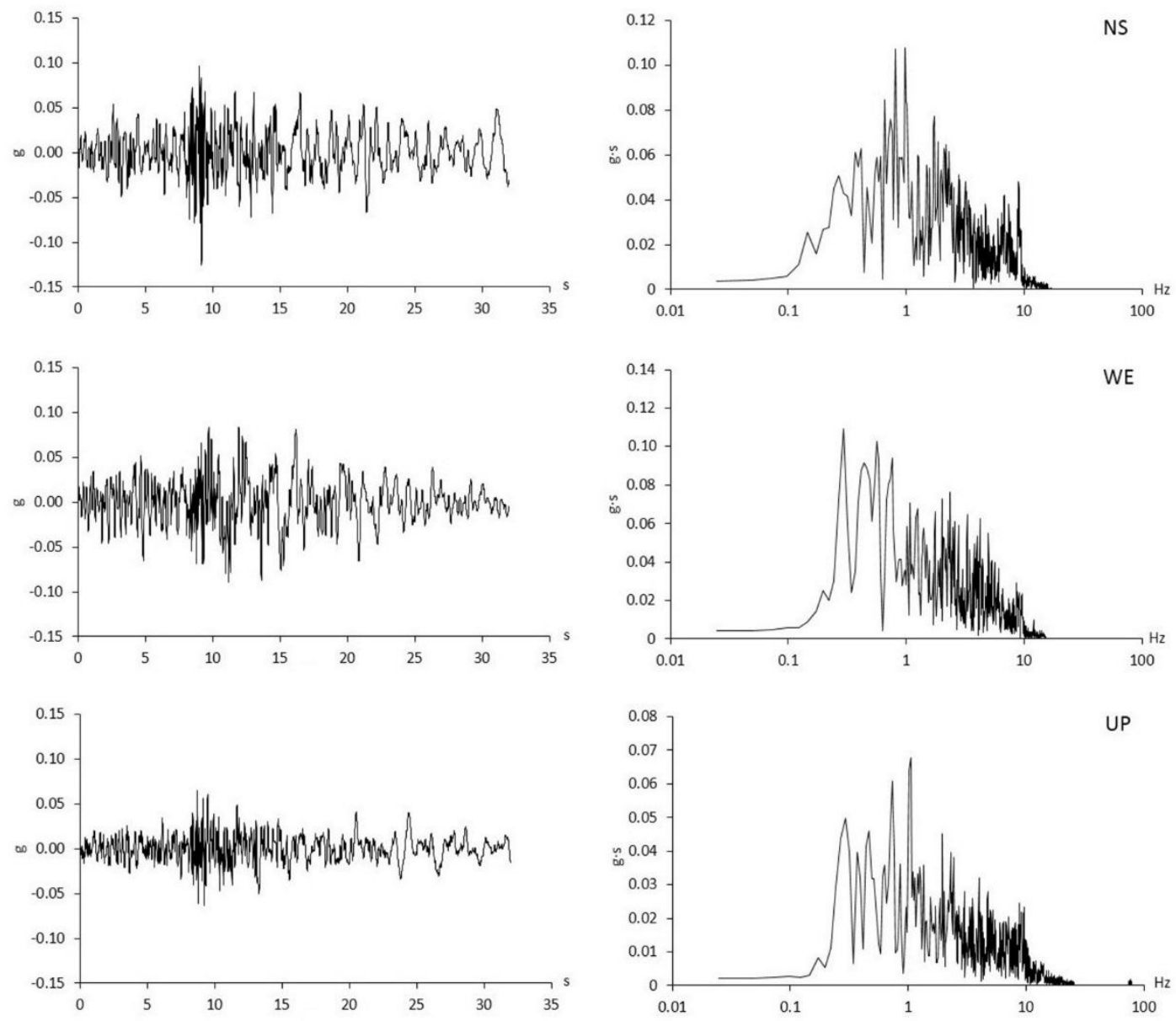

936 Fig.6 - Reference 3-component input used for the numerical modeling (by Guido Martini, ENEA 937 Italy): timehistories (left column) and Fast Fourier Transform (right column) of the horizontal (up 938 and middle) and vertical (down) components of the input. 


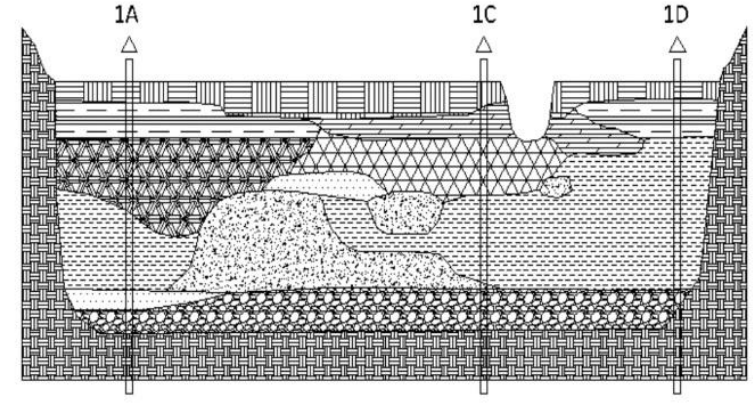

section 1

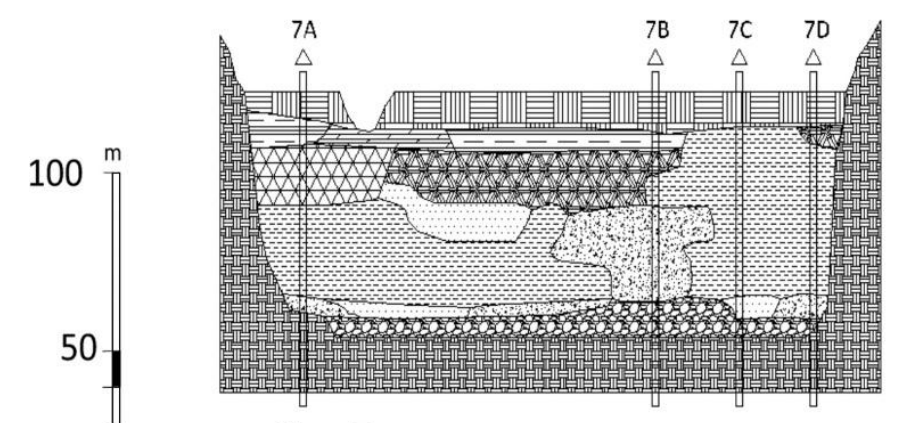

section 7

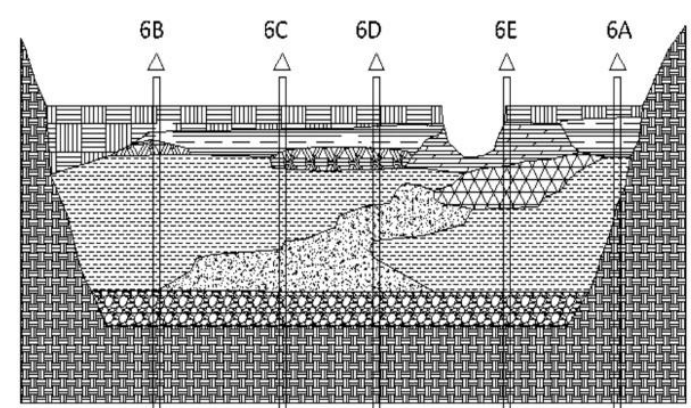

section 6

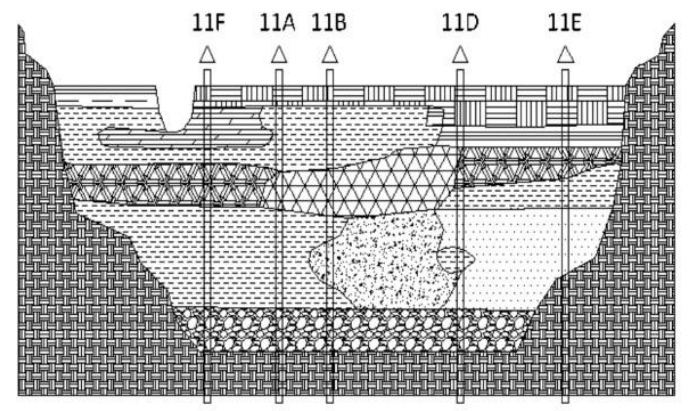

section 11

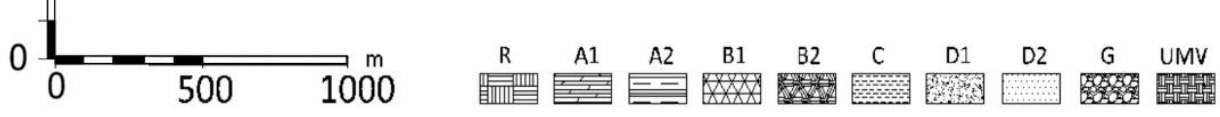

940 Fig.7 - Engineering-geological cross sections along the traces 1, 6, 7 and 11 (see Fig.1 for location) used for the performed 2D numerical models. The 17 soil columns considered for computing the

$942 \Delta \Gamma_{1 \mathrm{D} \_2 \mathrm{D}}$ index are also shown (see also Fig.1 for location). 

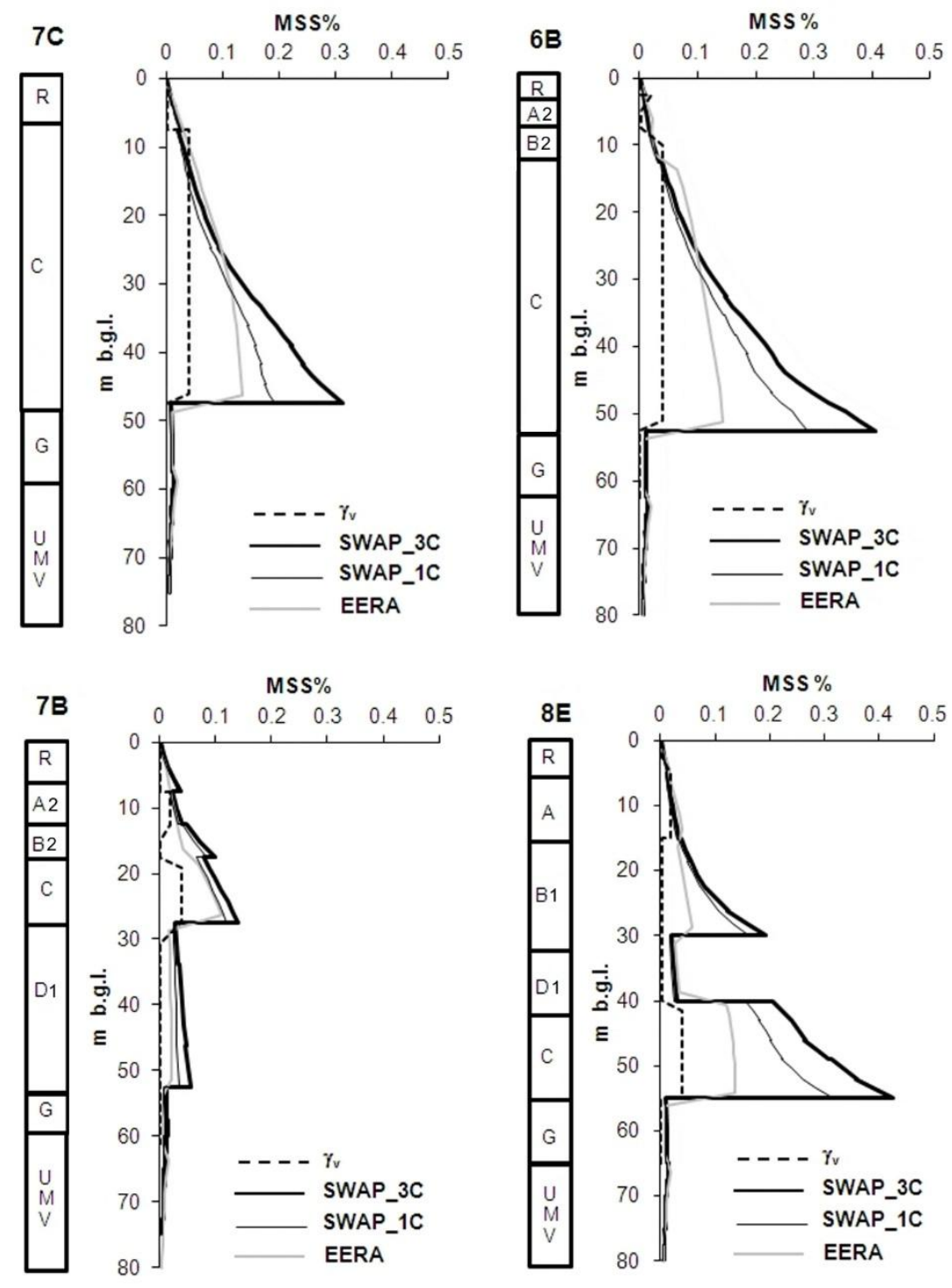

944 Fig.8 - MSS distribution along some of the 48 modeled soil columns (see Fig.1 for location) by the 945 codes EERA and SWAP; in the case of SWAP the MSS distribution for both the 1-component input 946 (SWAP_1C) and for the 3-component input (SWAP_3C) are distinguished. 
(a)

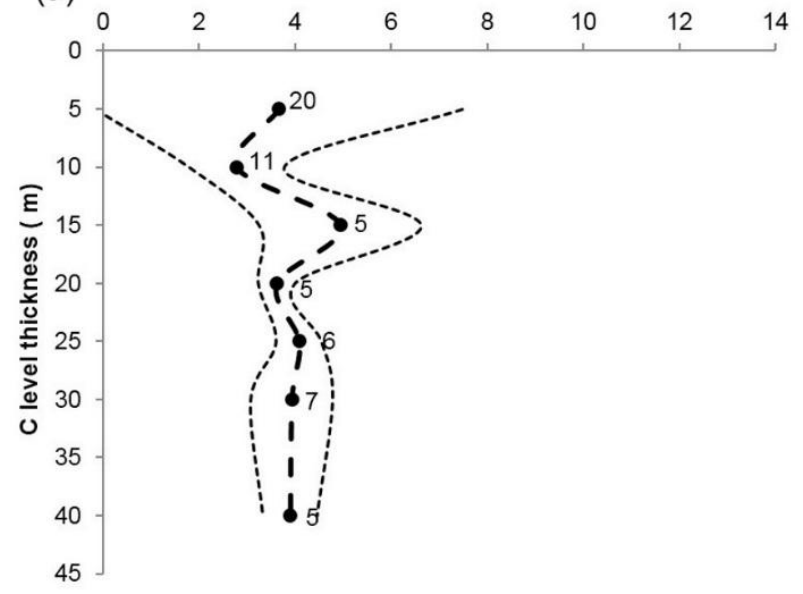

(b) MSS/ $\mathrm{y}_{\mathrm{v}}$ SWAP (octaedral)

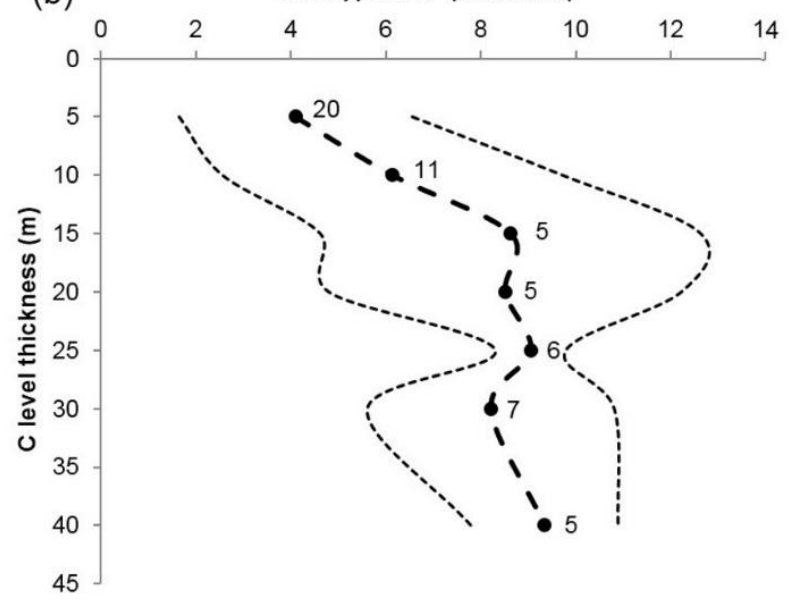

947

948 Fig.9 - Average MSS $/ \gamma_{v}$ vs. the C layer thickness distributions (+/- standard deviation, dashed lines)

949 in the case of: a) EERA (1-component input); b) SWAP (3-component input). The labels close to 950 the black circles indicate the number of cases considered for the mean. 

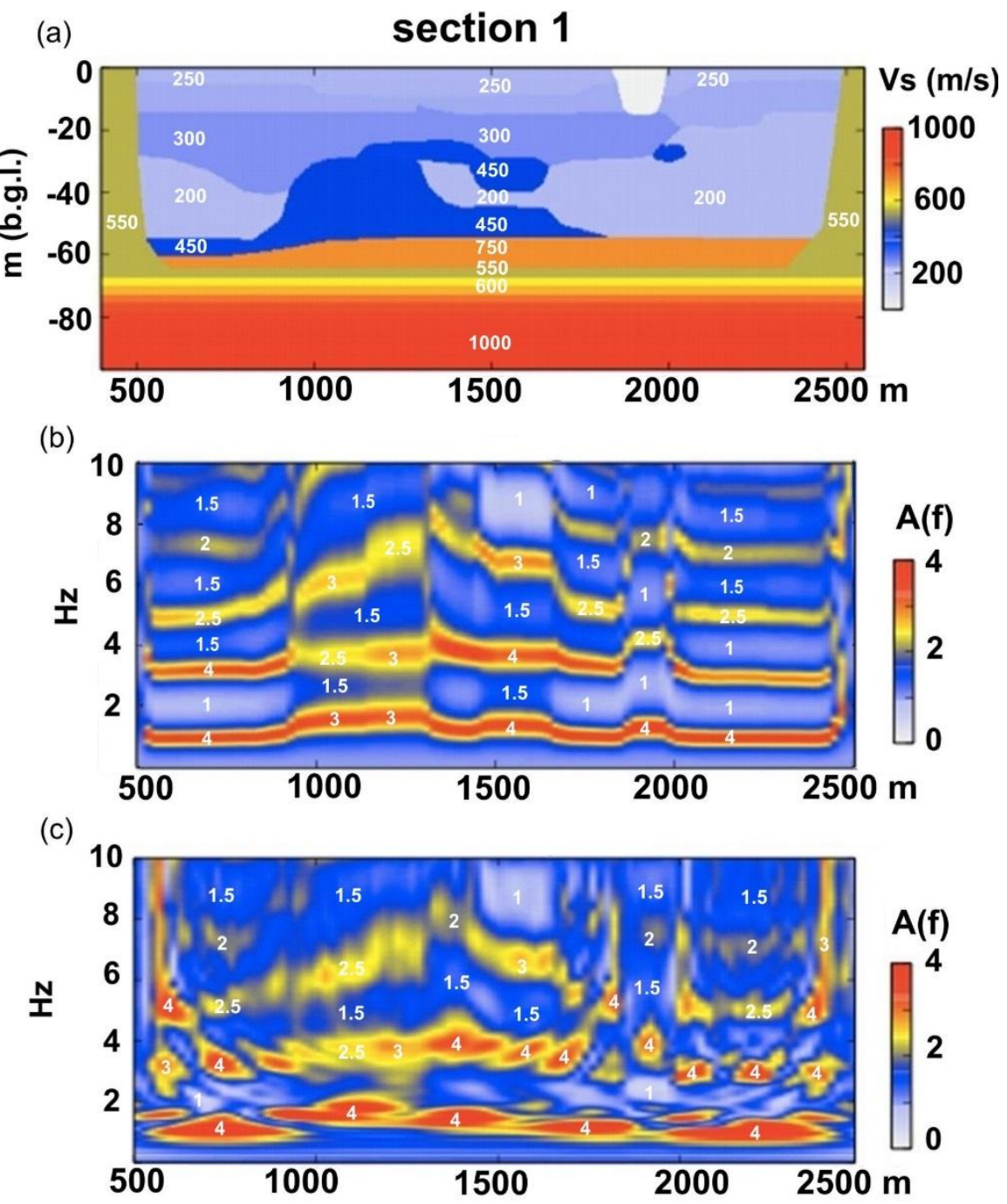

951

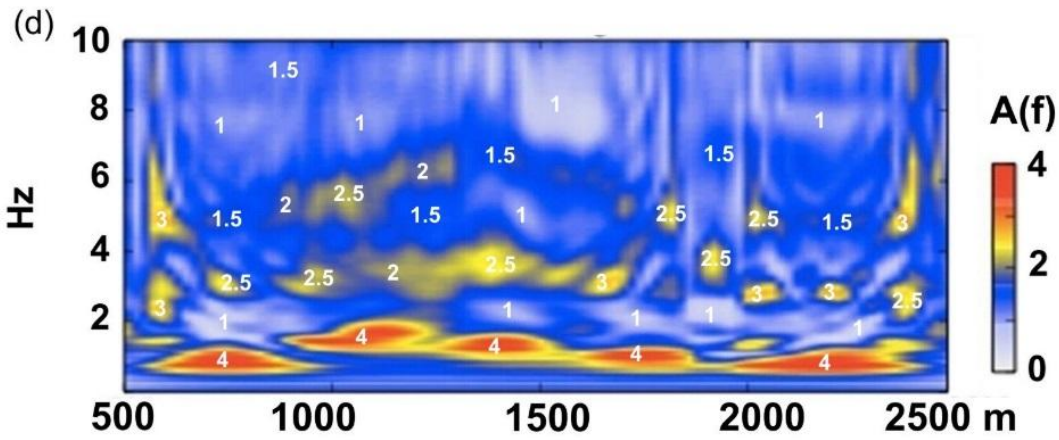

952 Fig.10 - Outputs of the 2D numerical model performed along section 1 of Fig.7: a) Vs value 953 distribution in the numerical domain; b) A(f) function from the 1D viscoelastic solution; c) A(f) 954 function from the $2 \mathrm{D}$ viscoelastic solution; d) A(f) function from the $2 \mathrm{D}$ viscoplastic solution. The 955 A(f) functions are plotted for the basin width only. 

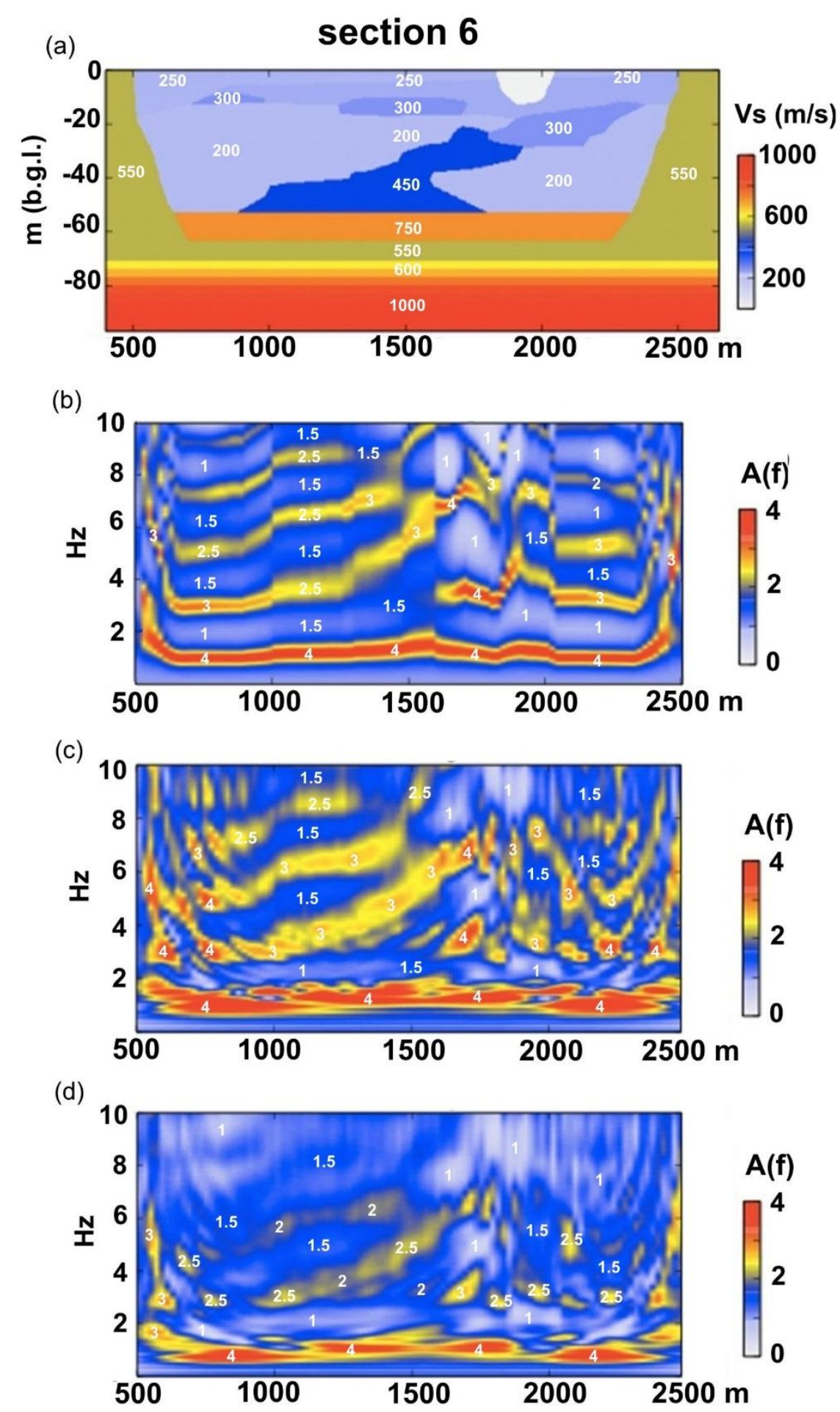

957 Fig.11 - Outputs of the 2D numerical model performed along section 6 of Fig.7: a) Vs value 958 distribution in the numerical domain; b) A(f) function from the $1 \mathrm{D}$ viscoelastic solution; c) $\mathrm{A}(\mathrm{f})$ 959 function from the $2 \mathrm{D}$ viscoelastic solution; d) $\mathrm{A}(\mathrm{f})$ function from the $2 \mathrm{D}$ viscoplastic solution. The 960 A(f) functions are plotted for the basin width only. 

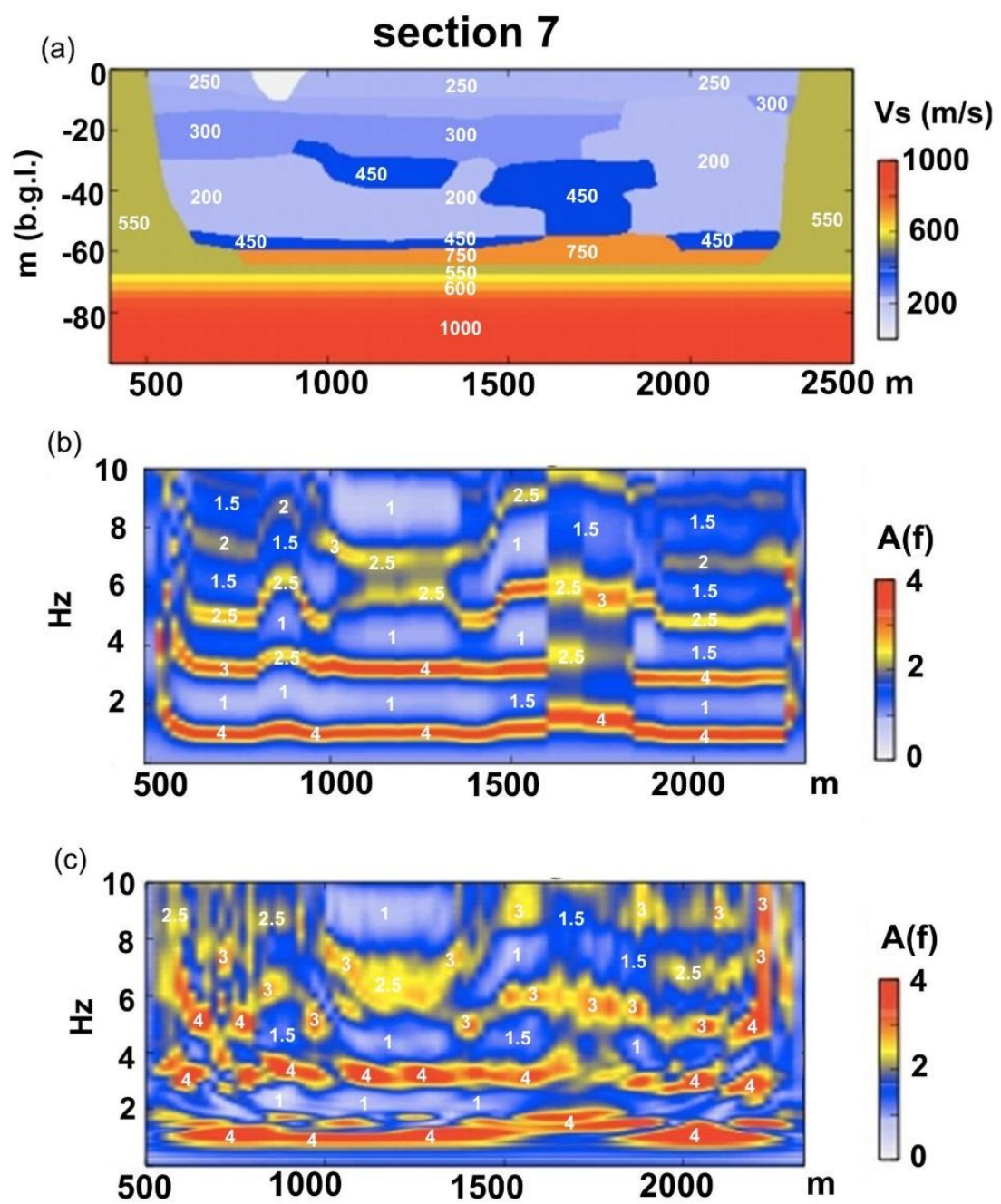

961

(d)

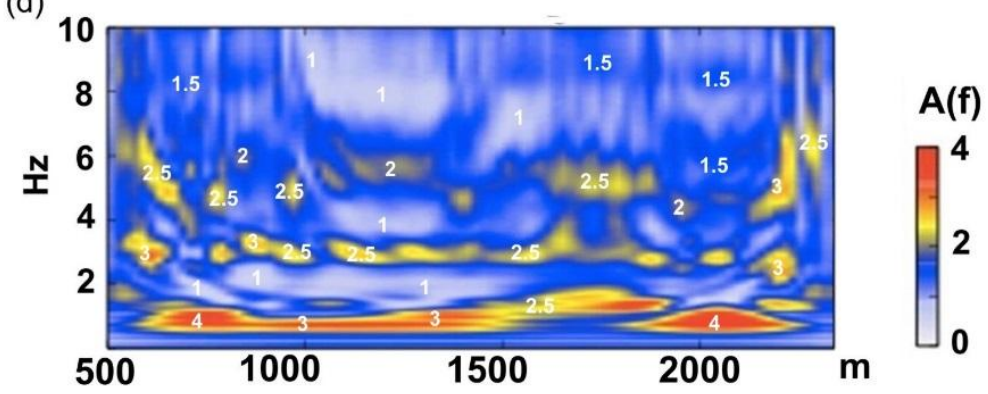

962 Fig.12 - Outputs of the 2D numerical model performed along section 7 of Fig.7: a) Vs value 963 distribution in the numerical domain; b) A(f) function from the 1D viscoelastic solution; c) A(f) 964 function from the 2D viscoelastic solution; d) A(f) function from the 2D viscoplastic solution. The $965 \mathrm{~A}(\mathrm{f})$ functions are plotted for the basin width only. 


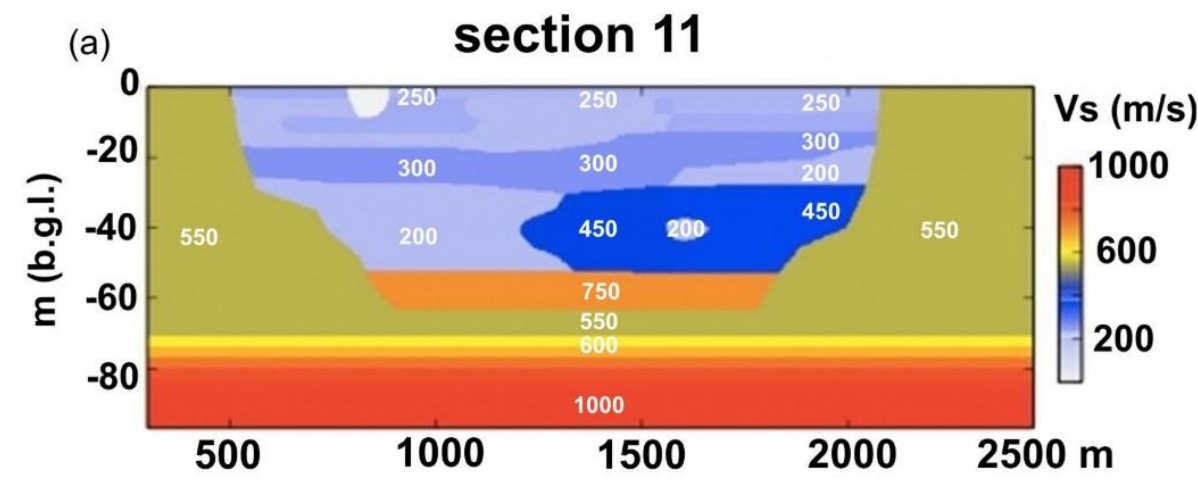

(b)

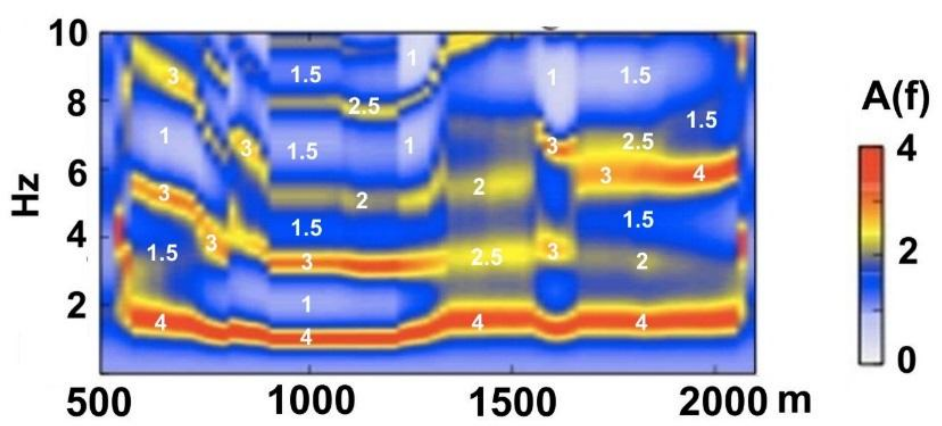

(c)

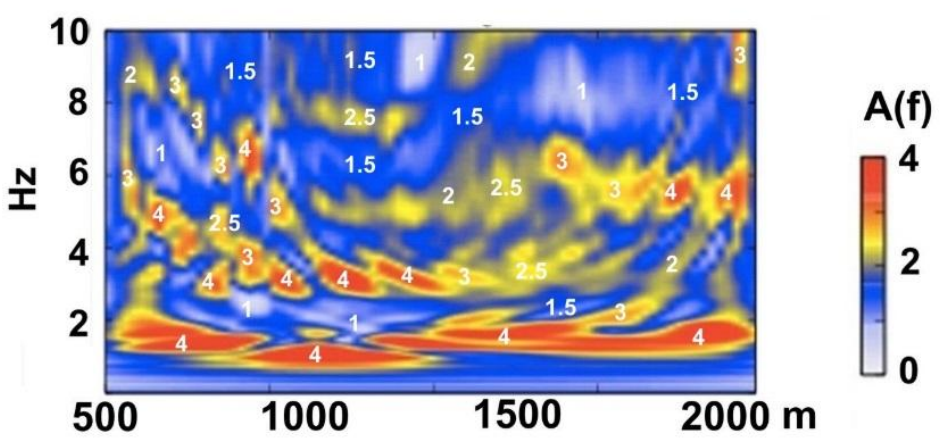

(d)

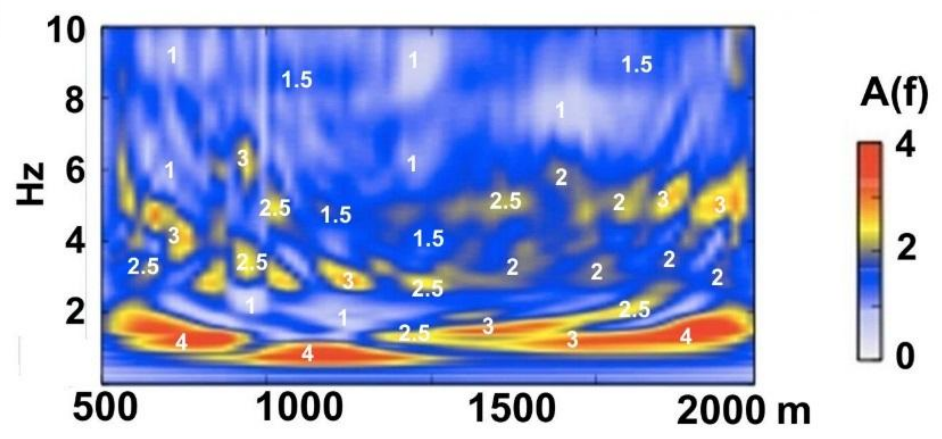

967 Fig.13 - Outputs of the 2D numerical model performed along section 11 of Fig.7: a) Vs value 968 distribution in the numerical domain; b) A(f) function from the $1 \mathrm{D}$ viscoelastic solution; c) $\mathrm{A}(\mathrm{f})$ 969 function from the $2 \mathrm{D}$ viscoelastic solution; d) A(f) function from the $2 \mathrm{D}$ viscoplastic solution. The 970 A(f) functions are plotted for the basin width only. 

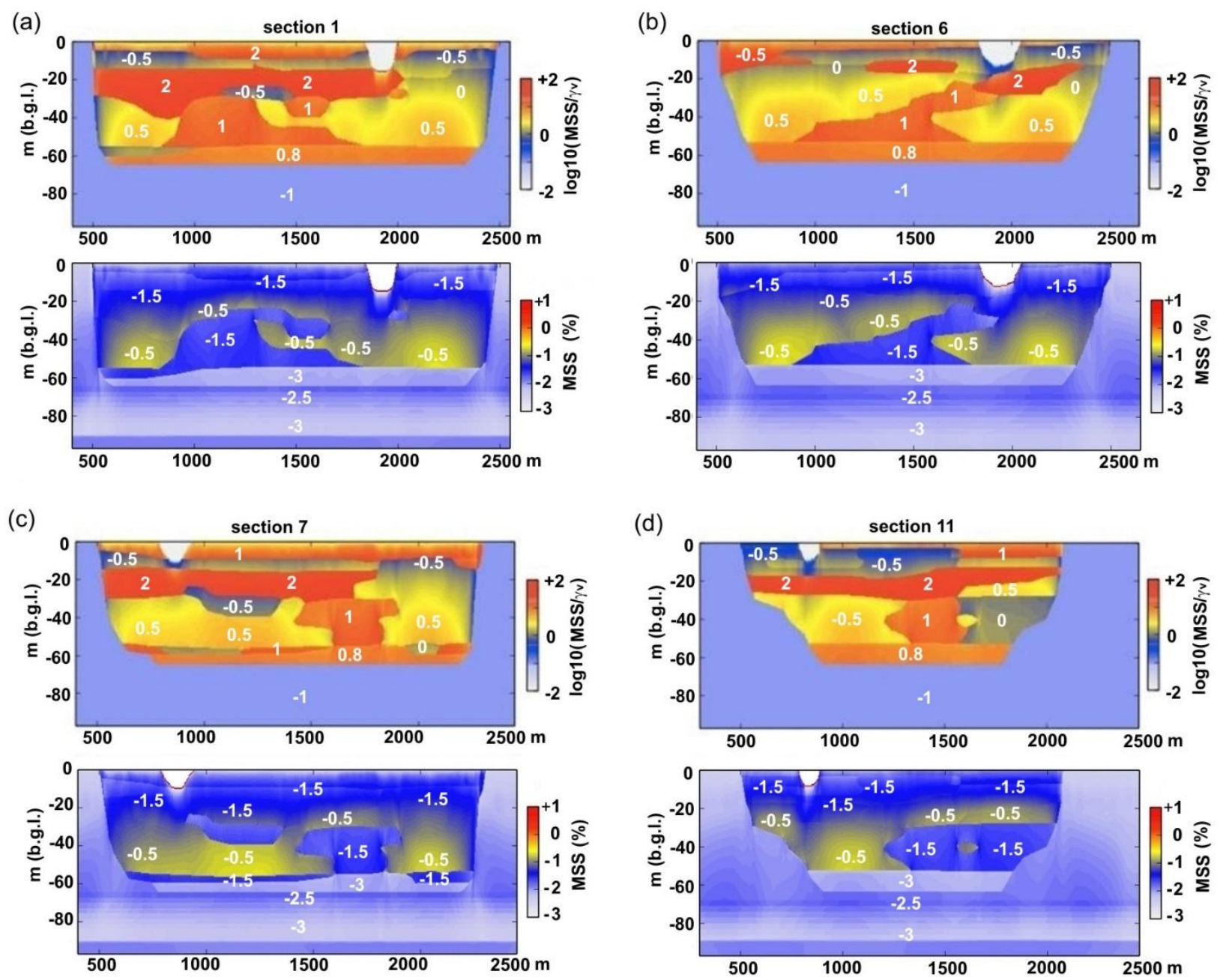

972 Fig.14 - MSS $/ \gamma_{v}$ ratio distributions resulting by the 2D numerical models for section 1 (a), 6 (b), 7

973 (c) and 11 (d); the MSS distributions within the models are also reported. 


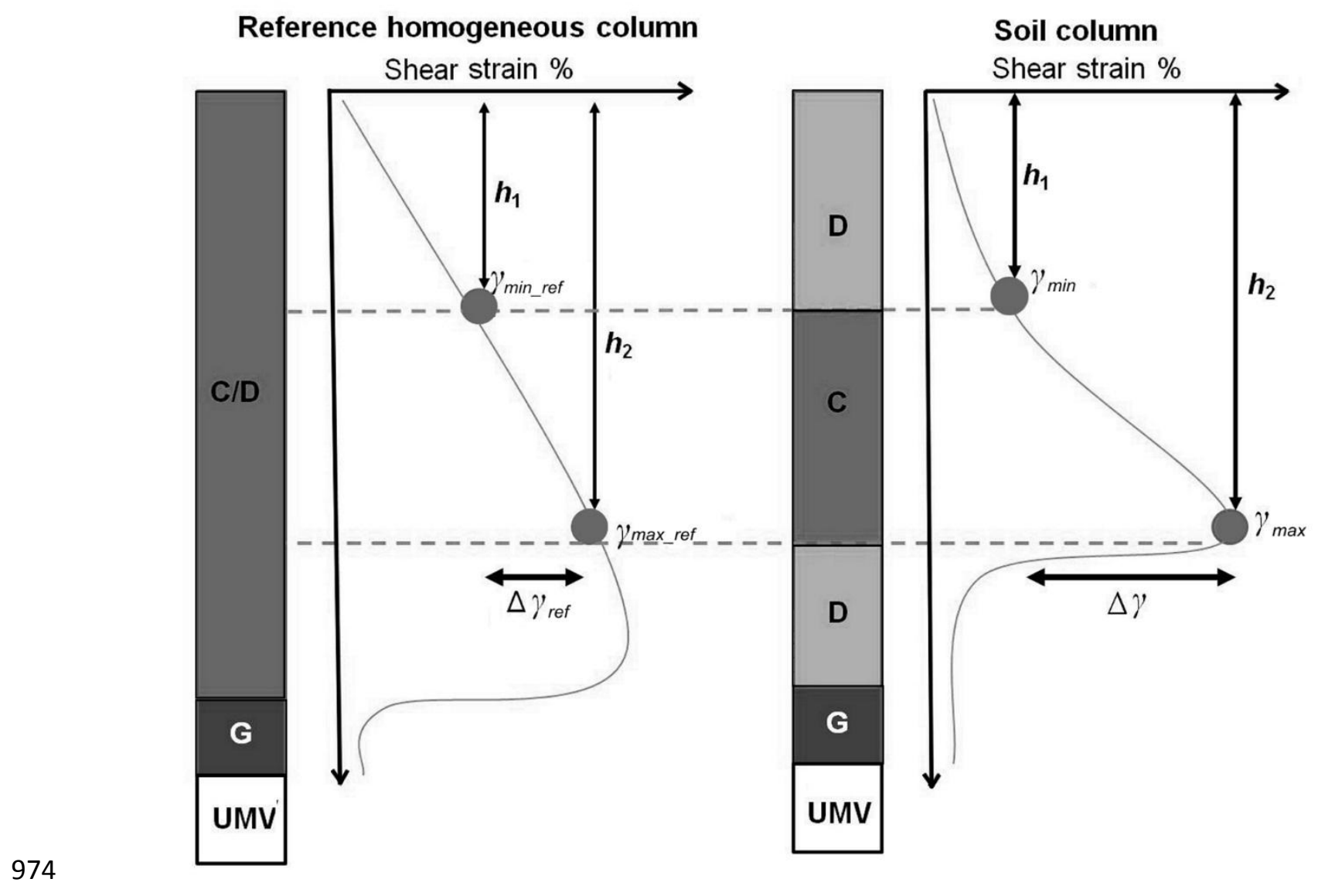

975 Fig. 15 - Sketch that illustrates the $\Delta \Gamma$ index obtained by subtracting the SSCI index computed for 976 the C layer in a general column to the same index computed for the corresponding reference 977 column. 

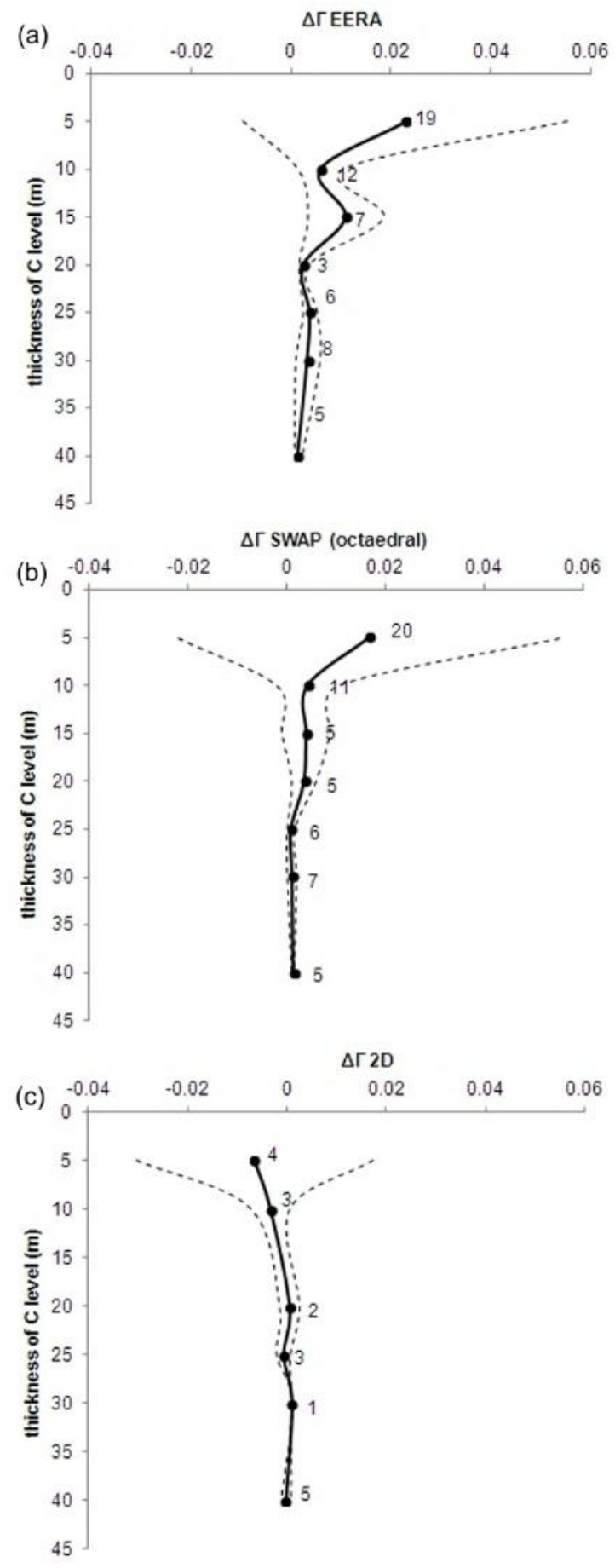

979 Fig.16 $-\Delta \Gamma$ index distributions vs. $C$ layer thickness as they result from the EERA, SWAP_3C (for 980 a 3-component input) and 2D numerical models. The outputs are referred to the 48 soil columns of 981 Fig.1 for the 1D models and to the 17 soil columns of Fig.7 for the 2D models. The labels close to 982 the black circles indicate the number of cases considered for the mean. 


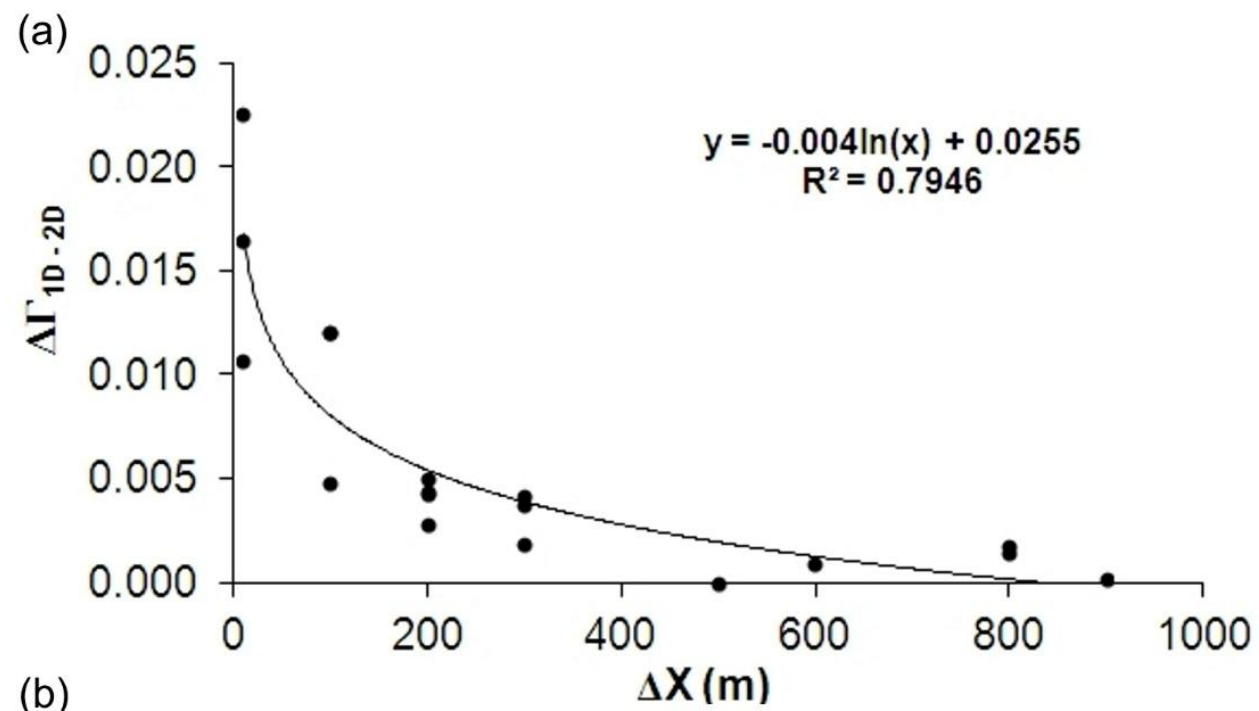

(b)

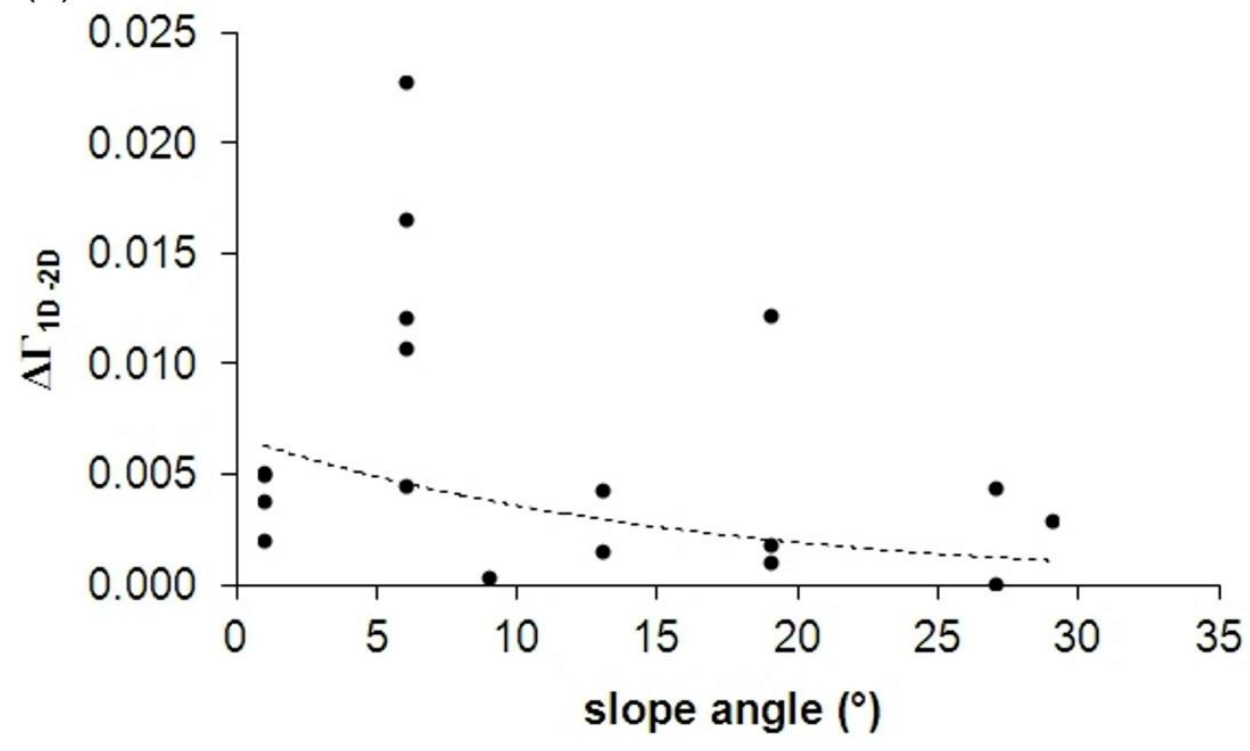

983

984 Fig, 17 - a) $\Delta \Gamma_{1 D_{2} \text { D }}$ index distributions vs. the maximum distance of the $\mathrm{C}$ layer from the closest

985 high-impedance $\left(\Delta \mathrm{Vs}_{\mathrm{s}}>200 \mathrm{~m} / \mathrm{s}\right)$ lateral contact $(\Delta \mathrm{X})$ and $\left.\mathrm{b}\right) \Delta \Gamma_{1 \mathrm{D}_{-} 2 \mathrm{D}}$ index distributions vs. the 986 inclination angles of the slope buried below the alluvial deposits in the Tiber River valley at Rome 987 historical center. 


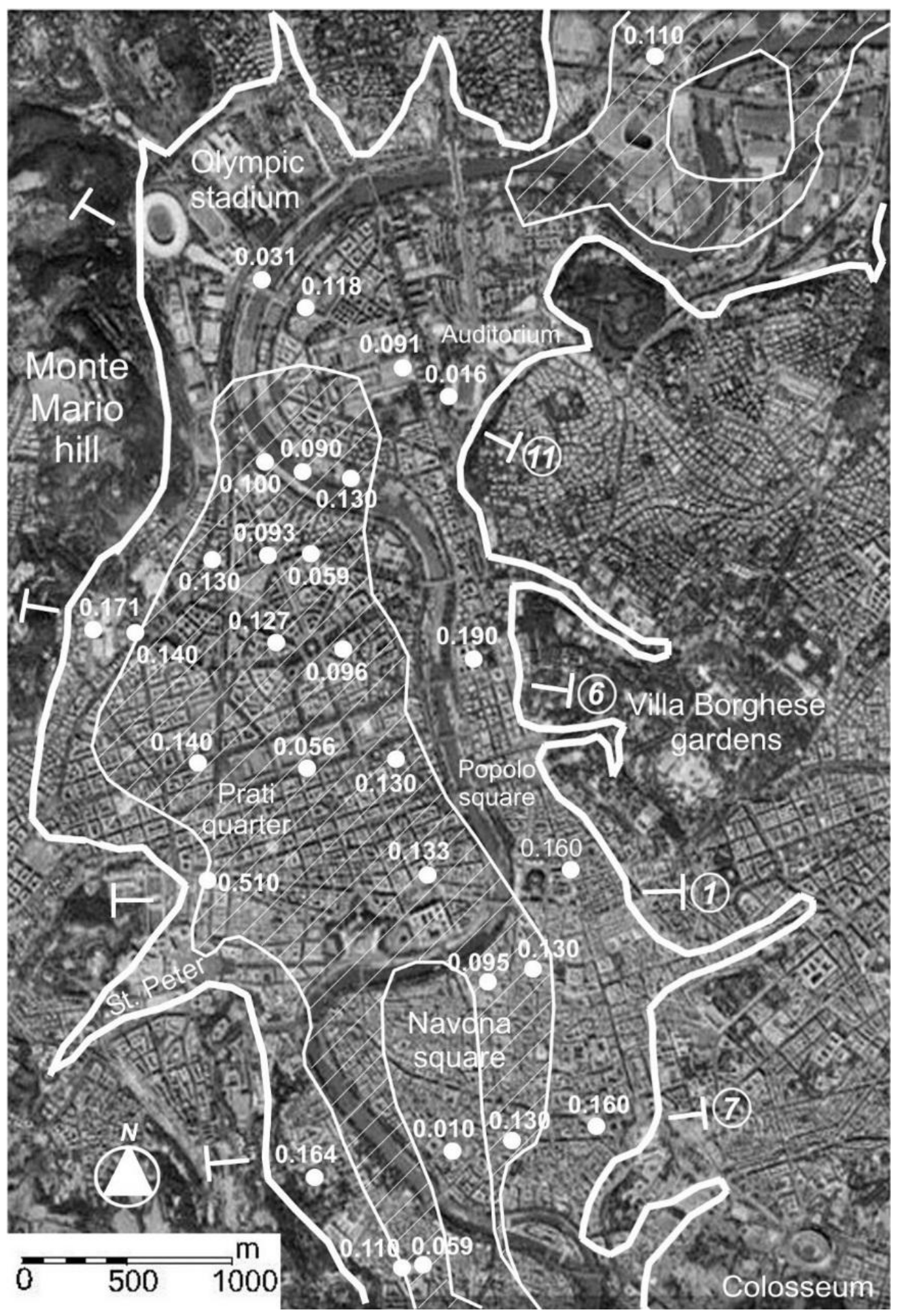

989 Fig.18 - GoogleEarth satellite view of the Rome historical center in which the Tiber River alluvial 990 deposits are bounded by a bold white lines and the zones suitable for 1D (areas with the white lines) 991 and 2D (areas without lines) shear strain effects are mapped; MSS values expected in the C layer 992 for the 475-years earthquake scenario are also reported. 


\begin{tabular}{|c|c|c|c|c|c|c|c|c|c|c|c|c|c|c|}
\hline \multirow{2}{*}{$\begin{array}{c}n^{\circ} \\
1\end{array}$} & \multirow{2}{*}{$\begin{array}{l}\text { ID } \\
2 B\end{array}$} & \multirow{2}{*}{\begin{tabular}{|c|}
$\begin{array}{c}\text { number of } \\
\text { layers }\end{array}$ \\
8 \\
\end{tabular}} & \multirow{2}{*}{\begin{tabular}{|c}
$\begin{array}{c}\text { total thickness } \\
(\mathrm{m})\end{array}$ \\
70.0 \\
\end{tabular}} & \multicolumn{8}{|c|}{ soil column stratigraphy (lithotechnical level, thickness (m)) } & \multirow{2}{*}{\begin{tabular}{|c|}
$\%$ clay \\
21 \\
\end{tabular}} & \multirow{2}{*}{\begin{tabular}{c|}
$\%$ sand \\
79 \\
\end{tabular}} & \multirow{2}{*}{$\begin{array}{c}\text { soil } \\
\text { composition of } \\
\text { the reference } \\
\text { D }\end{array}$} \\
\hline & & & & $\mathrm{R}, 10$ & $\mathrm{~A} 2,5$ & $\mathrm{~A} 1,5$ & $\mathrm{~B} 1,15$ & D1, 10 & $\mathrm{C}, 5$ & D1, 10 & G, 10 & & & \\
\hline 2 & $5 \mathrm{~B}$ & 8 & 65.0 & $\mathrm{R}, 5$ & $\mathrm{~A} 2,5$ & $\mathrm{~A} 1,10$ & $\mathrm{~B} 1,5$ & $\mathrm{D} 1,5$ & C, 10 & D1, 15 & $G, 10$ & 38 & 62 & $D$ \\
\hline 3 & $9 \mathrm{~A}$ & 8 & 65.0 & $\mathrm{R}, 10$ & $\mathrm{~A} 1,5$ & $\mathrm{~A} 2,5$ & $\mathrm{~B} 1,5$ & $\mathrm{C}, 5$ & \begin{tabular}{|l|}
$\mathrm{D} 1,10$ \\
\end{tabular} & C, 15 & G, 10 & 46 & 54 & $D$ \\
\hline 4 & $12 \mathrm{E}$ & 8 & 62.5 & $\mathrm{R}, 2.5$ & $\mathrm{~A} 1,10$ & $\mathrm{~A} 2,5$ & C, 10 & D1, 10 & $\mathrm{C}, 5$ & D1, 10 & G, 10 & 48 & 52 & $D$ \\
\hline 5 & $3 \mathrm{C}$ & 8 & 62.5 & $\mathrm{R}, 2.5$ & $\mathrm{~A} 2,5$ & $\mathrm{~A} 1, \mathrm{C}$, & $\mathrm{B} 1,5$ & $\mathrm{C}, 5$ & D1, 20 & C, 10 & $\mathrm{G}, 10$ & 40 & 60 & $D$ \\
\hline 6 & $5 \mathrm{C}$ & 8 & 62.5 & $\mathrm{R}, 2.5$ & $\mathrm{~A} 1,5$ & $\mathrm{~A} 2,5$ & $\mathrm{~B} 1,10$ & $C, 5$ & D1, 10 & C, 15 & G, 10 & 48 & 52 & $D$ \\
\hline 7 & $6 \mathrm{D}$ & 8 & 62.5 & $\mathrm{R}, 2.5$ & $\mathrm{~A} 2,10$ & $\mathrm{~B} 2,5$ & $\mathrm{C}, 5$ & D1, 15 & $\mathrm{C}, 5$ & D1, 10 & G. 10 & 32 & 68 & $D$ \\
\hline 8 & $10 \mathrm{~A}$ & 8 & 60.0 & $\mathrm{R}, 5$ & $\mathrm{~A} 1,5$ & $C, 5$ & $\mathrm{~B} 2,5$ & $\mathrm{D} 1,5$ & \begin{tabular}{|l|}
$\mathrm{D} 2,15$ \\
\end{tabular} & C, 10 & $\mathrm{G}, 10$ & 58 & 42 & $\mathrm{C}$ \\
\hline 9 & $9 D$ & 8 & 60.0 & $\mathrm{R}, 5$ & $\mathrm{~A} 1,5$ & $\mathrm{~A} 2,5$ & $\mathrm{C}, 5$ & $\mathrm{D} 1,5$ & \begin{tabular}{|l|} 
C, 15 \\
\end{tabular} & D1, 10 & $\mathrm{G}, 10$ & 50 & 50 & $\mathrm{C}$ \\
\hline 10 & $11 \mathrm{D}$ & 8 & 57.5 & $\mathrm{R}, 2.5$ & $\mathrm{~A} 2,5$ & B1, 10 & $\mathrm{C}, 5$ & $\mathrm{D} 2,10$ & $\mathrm{C}, 5$ & D1, 10 & G. 10 & 43 & 57 & $D$ \\
\hline 11 & $2 \mathrm{D}$ & 7 & 67.5 & $\mathrm{R}, 7.5$ & $\mathrm{~A} 2,10$ & $\mathrm{C}, 5$ & $\mathrm{~B} 1,5$ & $\mathrm{C}, 5$ & \begin{tabular}{|l|}
$\mathrm{D} 1,25$ \\
\end{tabular} & G, 10 & & 30 & 70 & $D$ \\
\hline 12 & $9 \mathrm{C}$ & 7 & 67.5 & $\mathrm{R}, 7.5$ & $\mathrm{~A} 1,10$ & $\mathrm{~B} 1,15$ & \begin{tabular}{|l|} 
D1, 10 \\
\end{tabular} & $C, 5$ & \begin{tabular}{|l|}
$\mathrm{D} 1,10$ \\
\end{tabular} & $\mathrm{G}, 10$ & & 33 & 67 & $\mathrm{D}$ \\
\hline 13 & $10 \mathrm{D}$ & 7 & 62.5 & $\mathrm{R}, 2.5$ & \begin{tabular}{|l|}
$\mathrm{A} 2,5$ \\
\end{tabular} & \begin{tabular}{|l|}
$\mathrm{A} 1,10$ \\
\end{tabular} & \begin{tabular}{|l|}
$\mathrm{B} 1,10$ \\
\end{tabular} & \begin{tabular}{|l|}
$\mathrm{D} 1,10$ \\
\end{tabular} & \begin{tabular}{|l|}
$\mathrm{C}, 15$ \\
\end{tabular} & $\mathrm{G}, 10$ & & 48 & 52 & $D$ \\
\hline 14 & $10 \mathrm{~B}$ & 7 & 62.5 & $\mathrm{R}, 2.5$ & $\mathrm{~A} 2,5$ & $\mathrm{~A} 1,5$ & C, 10 & D2, 20 & C, 10 & $\mathrm{G}, 10$ & & 64 & 36 & $\mathrm{C}$ \\
\hline 15 & $10 \mathrm{C}$ & 7 & 62.5 & $\mathrm{R}, 2.5$ & $\mathrm{~A} 2,10$ & $\mathrm{~B} 2,5$ & $\mathrm{C}, 5$ & D1, 30 & $\mathrm{D} 2,5$ & $\mathrm{G}, 5$ & & 32 & 68 & $D$ \\
\hline 16 & $12 \mathrm{C}$ & 7 & 62.5 & $\mathrm{R}, 2.5$ & $\mathrm{~A} 2,5$ & $\mathrm{~B} 2,5$ & $\mathrm{~A} 2,5$ & C, 20 & D1, 15 & G, 10 & & 48 & 52 & $D$ \\
\hline 17 & $12 \mathrm{D}$ & 7 & 62.5 & $\mathrm{R}, 2.5$ & $\mathrm{~A} 2,5$ & $\mathrm{~B} 2,5$ & $\mathrm{~A} 2,5$ & C, 10 & \begin{tabular}{|l|}
$\mathrm{D} 1,25$ \\
\end{tabular} & $\mathrm{G}, 10$ & & 32 & 68 & $D$ \\
\hline 18 & $5 \mathrm{~A}$ & 7 & 62.5 & $\mathrm{R}, 2.5$ & $\mathrm{~A} 2,5$ & $\mathrm{~A} 1,5$ & C, 10 & $\mathrm{~B} 1,5$ & C, 25 & $\mathrm{G}, 10$ & & 88 & 12 & $\mathrm{C}$ \\
\hline 19 & $9 \mathrm{E}$ & 7 & 62.5 & $\mathrm{R}, 7.5$ & $\mathrm{~A} 1,5$ & C, 5 & D1, 5 & C, 20 & D1, 10 & $\mathrm{G}, 10$ & & 64 & 36 & $\mathrm{C}$ \\
\hline 20 & $8 D$ & 6 & 65.0 & $\mathrm{R}, 5$ & $\mathrm{~A} 1,5$ & $\mathrm{~B} 2,10$ & C, 10 & D1, 25 & $\mathrm{G}, 10$ & & & 23 & 77 & $\mathrm{D}$ \\
\hline 21 & $8 \mathrm{E}$ & 6 & 65.0 & $\mathrm{R}, 5$ & $\mathrm{~A} 1,10$ & $\mathrm{~B} 1,15$ & \begin{tabular}{|l|} 
D1, 10 \\
\end{tabular} & C, 15 & G, 10 & & & 38 & 62 & $D$ \\
\hline 22 & $11 \mathrm{~B}$ & 6 & 62.5 & $\mathrm{R}, 2.5$ & \begin{tabular}{|l|}
$\mathrm{A} 1,15$ \\
\end{tabular} & \begin{tabular}{|l|}
$\mathrm{B} 1,10$ \\
\end{tabular} & \begin{tabular}{|l|}
$\mathrm{D} 1,15$ \\
\end{tabular} & C, 10 & G, 10 & & & 40 & 60 & $D$ \\
\hline 23 & $12 \mathrm{~B}$ & 6 & 62.5 & $\mathrm{R}, 2.5$ & $\mathrm{~A} 2,5$ & $\mathrm{~B} 2,5$ & C, 30 & D1, 10 & G, 10 & & & 56 & 44 & $\mathrm{C}$ \\
\hline 24 & $1 \mathrm{~A}$ & 6 & 62.5 & $\mathrm{R}, 2.5$ & $\mathrm{~A} 2,10$ & B2, 25 & C, 15 & $\mathrm{D} 2,5$ & G, 5 & & & 48 & 52 & $D$ \\
\hline 25 & $2 \mathrm{C}$ & 6 & 62.5 & $\mathrm{R}, 2.5$ & $\mathrm{~A} 1,10$ & $\mathrm{~A} 2,5$ & C, 5 & D1, 30 & G, 10 & & & 32 & 68 & D \\
\hline 26 & $3 \mathrm{~A}$ & 6 & 62.5 & $\mathrm{R}, 2.5$ & $\mathrm{~A} 1,10$ & $\mathrm{~A} 2,5$ & B1, 10 & C, 30 & $\mathrm{G}, 5$ & & & 72 & 28 & $C$ \\
\hline 27 & $3 \mathrm{~B}$ & 6 & 62.5 & $\mathrm{R}, 2.5$ & $A 2,5$ & $\mathrm{~A} 1,5$ & B1, 15 & $\mathrm{C}, 30$ & $\mathrm{G}, 5$ & & & 64 & 36 & $\mathrm{C}$ \\
\hline 28 & $6 \mathrm{C}$ & 6 & 62.5 & $\mathrm{R}, 2.5$ & \begin{tabular}{|l|}
$\mathrm{A} 2,10$ \\
\end{tabular} & $B 2,5$ & C, 20 & \begin{tabular}{|l|} 
D1, 15 \\
\end{tabular} & G, 10 & & & 48 & 52 & $D$ \\
\hline 29 & $7 \mathrm{~A}$ & 6 & 62.5 & $\mathrm{R}, 2.5$ & $\mathrm{~A} 1,10$ & B1, 15 & C, 25 & $\mathrm{D} 2,5$ & G, 5 & & & 64 & 36 & C \\
\hline 30 & $8 \mathrm{~A}$ & 6 & 62.5 & $\mathrm{R}, 2.5$ & $A 2,5$ & $\mathrm{~B} 2,5$ & C, 30 & D1, 10 & G, 10 & & & 56 & 44 & $\mathrm{C}$ \\
\hline 31 & $7 \mathrm{~B}$ & 6 & 60.0 & $\mathrm{R}, 10$ & $\mathrm{~A} 2,5$ & $\mathrm{~B} 2,5$ & C, 10 & D1, 25 & G, 5 & & & 25 & 75 & $D$ \\
\hline 32 & $8 \mathrm{C}$ & 6 & 60.0 & $\mathrm{~A} 2,5$ & $\mathrm{~A} 1,5$ & $\mathrm{~B} 2,5$ & C, 25 & D1, 10 & G, 10 & & & 58 & 42 & C \\
\hline 33 & $10 \mathrm{E}$ & 6 & 57.5 & $\mathrm{R}, 2.5$ & $\mathrm{~A} 2,5$ & $\mathrm{~A} 1,5$ & $\mathrm{~B} 1,15$ & $\mathrm{C}, 20$ & $\mathrm{G}, 10$ & & & 52 & 48 & $\mathrm{C}$ \\
\hline 34 & $11 \mathrm{E}$ & 6 & 57.5 & $R, 2.5$ & $\mathrm{~A} 2,5$ & \begin{tabular}{|l|}
$\mathrm{B} 2,10$ \\
\end{tabular} & $\mathrm{C}, 5$ & \begin{tabular}{|l|}
$\mathrm{D} 2,25$ \\
\end{tabular} & G, 10 & & & 60 & 40 & $\mathrm{C}$ \\
\hline 35 & $2 \mathrm{~A}$ & 6 & 55.0 & $\mathrm{~A} 2,10$ & $\mathrm{~A} 1,5$ & C. 5 & $\mathrm{D} 2,5$ & $\mathrm{C}, 25$ & G, 5 & & & 90 & 10 & $\mathrm{C}$ \\
\hline 36 & $6 \mathrm{E}$ & 5 & 70.0 & $\mathrm{R}, 10$ & A2, 10 & B1, 10 & C, 30 & G, 10 & & & & 57 & 43 & $\mathrm{C}$ \\
\hline 37 & $3 E$ & 5 & 67.5 & $\mathrm{R}, 2.5$ & $\mathrm{~A} 2,10$ & C, 15 & D1, 30 & G, 10 & & & & 37 & 63 & $D$ \\
\hline 38 & $11 \mathrm{~A}$ & 5 & 62.5 & R. 2.5 & A1, 15 & $\mathrm{~B} 1,10$ & C. 25 & $\mathrm{G}, 10$ & & & & 64 & 36 & C \\
\hline 39 & $1 \mathrm{C}$ & 5 & 62.5 & $\mathrm{R}, 2.5$ & A1, 10 & \begin{tabular}{|l|}
$\mathrm{B} 1,15$ \\
\end{tabular} & C, 25 & $\mathrm{G}, 10$ & & & & 56 & 44 & $C$ \\
\hline 40 & $6 \mathrm{~B}$ & 5 & 62.5 & $\mathrm{R}, 2.5$ & $\mathrm{~A} 2,5$ & $\mathrm{~B} 2,5$ & C, 40 & $\mathrm{G}, 10$ & & & & 72 & 28 & $\mathrm{C}$ \\
\hline 41 & $9 \mathrm{~F}$ & 5 & 62.5 & $\mathrm{R}, 7.5$ & $\mathrm{~A} 2,5$ & $\mathrm{C}, 30$ & \begin{tabular}{|l|}
$\mathrm{D} 1,10$ \\
\end{tabular} & G, 10 & & & & 56 & 44 & $\mathrm{C}$ \\
\hline 42 & $8 \mathrm{~B}$ & 5 & 60.0 & $\mathrm{~A} 1,5$ & \begin{tabular}{|l|}
$\mathrm{B} 2,5$ \\
\end{tabular} & $\mathrm{C}, 30$ & \begin{tabular}{|l|}
$\mathrm{D} 1,10$ \\
\end{tabular} & $\mathrm{G}, 10$ & & & & 58 & 42 & $\mathrm{C}$ \\
\hline 43 & $6 \mathrm{~A}$ & 4 & 62.5 & $\mathrm{R}, 2.5$ & A2, 15 & C, 40 & $\mathrm{G}, 10$ & & & & & 88 & 12 & C \\
\hline 44 & $3 D$ & 4 & 60.0 & $\mathrm{~A} 1,15$ & $C, 5$ & D1, 30 & $\mathrm{G}, 10$ & & & & & 33 & 67 & $D$ \\
\hline 45 & $1 \mathrm{D}$ & 4 & 57.5 & $\mathrm{R}, 2.5$ & $\mathrm{~A} 2,10$ & $\mathrm{C}, 40$ & $\mathrm{G}, 5$ & & & & & 86 & 14 & C \\
\hline 46 & $7 \mathrm{D}$ & 4 & 57.5 & $\mathrm{R}, 7.5$ & C, 40 & $\mathrm{D} 1,5$ & G, 5 & & & & & 69 & 31 & $C$ \\
\hline 47 & $12 \mathrm{~A}$ & 3 & 65.0 & $\mathrm{~B} 2,15$ & C, 40 & $\mathrm{G}, 10$ & & & & & & 61 & 39 & $\mathrm{C}$ \\
\hline 48 & $7 \mathrm{C}$ & 3 & 60.0 & $\mathrm{R}, 10$ & C, 40 & $\mathrm{G}, 10$ & & & & & & 66 & 34 & $\mathrm{C}$ \\
\hline
\end{tabular}

994 Tab.1 - Log-stratigraphies of the 48 soil columns located in Fig.1 which were derived from the 3D

995 engineering-geology model of the Tiber River alluvial deposits at Rome historical center and that

996 were used for the here performed 1D numerical modeling. The ID of each column is referred to

997 Fig.1b and the codes of the soil layers are referred to Fig.3. The corresponding reference columns

998 for the $\Delta \Gamma$ index computation are also indicated. 